\title{
A sea surface reflectance model for (A)ATSR, and application to aerosol retrievals
}

\author{
A. M. Sayer, G. E. Thomas, and R. G. Grainger \\ Atmospheric, Oceanic \& Planetary Physics, Clarendon Laboratory, Parks Road, Oxford, OX1 3PU, UK \\ Received: 5 March 2010 - Published in Atmos. Meas. Tech. Discuss.: 18 March 2010 \\ Revised: 27 May 2010 - Accepted: 23 June 2010 - Published: 5 July 2010
}

\begin{abstract}
A model of the sea surface bidirectional reflectance distribution function (BRDF) is presented for the visible and near-IR channels (over the spectral range $550 \mathrm{~nm}$ to $1.6 \mu \mathrm{m}$ ) of the dual-viewing Along-Track Scanning Radiometers (ATSRs). The intended application is as part of the Oxford-RAL Aerosols and Clouds (ORAC) retrieval scheme. The model accounts for contributions to the observed reflectance from whitecaps, sun-glint and underlight. Uncertainties in the parametrisations used in the BRDF model are propagated through into the forward model and retrieved state. The new BRDF model offers improved coverage over previous methods, as retrievals are possible into the sunglint region, through the ATSR dual-viewing system. The new model has been applied in the ORAC aerosol retrieval algorithm to process Advanced ATSR (AATSR) data from September 2004 over the south-eastern Pacific. The assumed error budget is shown to be generally appropriate, meaning the retrieved states are consistent with the measurements and a priori assumptions. The resulting field of aerosol optical depth (AOD) is compared with colocated MODIS-Terra observations, AERONET observations at Tahiti, and cruises over the oceanic region. MODIS and AATSR show similar spatial distributions of AOD, although MODIS reports values which are larger and more variable. It is suggested that assumptions in the MODIS aerosol retrieval algorithm may lead to a positive bias in MODIS AOD of order 0.01 at $550 \mathrm{~nm}$ over ocean regions where the wind speed is high.
\end{abstract}

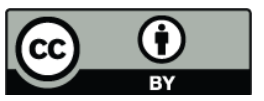

Correspondence to: A. M. Sayer (sayer@atm.ox.ac.uk)

\section{Introduction}

The Intergovernmental Panel for Climate Change (IPCC) has identified aerosols as among the most uncertain contributions to radiative forcing (Penner et al., 2001, Forster et al., 2007). As approximately $70 \%$ of the Earth's surface is covered by water, the accurate determination of aerosol loadings over ocean is critical to assess direct and indirect aerosol radiative effects. In the visible and near-infrared (nIR) spectral domains the ocean surface is dark, particularly compared to typical land surfaces, meaning the proportional atmospheric contribution to the signal measured by imaging radiometers at the top-of-atmosphere (TOA) is higher for the same aerosol loading. However, typical oceanic aerosol loadings are low (see, for example, Smirnov et al., 2009), meaning the surface contribution is non-negligible. An exception to the rule of the ocean being dark is found in sun-glint, whereby solar and satellite geometries lead to regions where the surface is very bright, typically in the tropics for nearnadir-viewing instruments. Parametrisations of sun-glint are largely based on the approach of Cox and Munk (1954a), and most aerosol retrieval algorithms use a glint formulation to identify and mask out glint-affected regions before processing. This has the effect of reducing the spatial coverage of the derived aerosol dataset, particularly in the tropics.

A notable exception to this is given by O'Brien and Mitchell (1988), who relied on the predictable spatial variation of surface reflectance within large cloud-free portions of the sun-glint region to peform aerosol and wind speed retrievals from Advanced Very High Resolution Radiometer (AVHRR) data. This methodology has, however, seen little application since.

Multiangle imaging instruments such as the Along-Track Scanning Radiometers (ATSRs), Multiangle Imaging SpectroRadiometer (MISR) and POLarization and Directionality

Published by Copernicus Publications on behalf of the European Geosciences Union. 
of the Earth's Reflectances (POLDER) allow for an improved representation of surface anisotropy in aerosol retrieval algorithms, although over oceans measurements from a single viewing geometry have been considered sufficient to derive useful aerosol information. The treatment of surface reflectance in some of these (single-view or multiview) algorithms is described below. Typically, the primary quantity retrieved is the aerosol optical depth (AOD) at a midvisible wavelength; many algorithms use a fixed surface reflectance, and some a fixed aerosol type. Regional differences exist in ocean aerosol climatologies from different sensors (for example, Thomas et al., 2010). Validation of aerosol optical depth over the open ocean is difficult; many land and coastal regions are well-represented by ground-based measurements taken by the AErosol RObotic NETwork (AERONET, Holben et al., 1998), while the Maritime Aerosol Network (MAN, Smirnov et al., 2009) of shipborne open ocean measurements is spatially and temporally sparser. It is likely that some of the differences between these satellite climatologies arise from the assumptions made about the ocean surface reflectance. Partially as a result of the comparative darkness of the ocean as compared to land surface reflectances, the various algorithms as summarised below tend to show little change since their early versions.

The over-ocean aerosol retrieval algorithm for the MODerate resolution Imaging Spectroradiometer (MODIS) is described first by Tanré et al. (1997), and the same basic algorithm is applied in the current Collection 5 of the dataset (Remer et al., 2005). The methodology is adapted from Koepke (1984), who defined glint, whitecap (foam) and underlight (scattering from dissolved pigments) contributions to the surface reflectance. The glint formulation of Cox and Munk (1954a) is used with a fixed wind speed, whitecap and underlight contribution, and a glint threshold is defined in which no retrievals are performed (unless heavy dust loading is detected, in which case the retrieval is attempted). The overall surface reflectance is fixed in the algorithm. Sediment masks are used to remove pixels of high sediment loading, which are not accounted for by the reflectance algorithm. The MISR ocean aerosol retrieval algorithm (Martonchik et al., 1998) also uses the method of Koepke (1984).

Veefkind and de Leeuw (1998) use a similar algorithm and fixed surface reflectance to retrieve AOD over ocean as a mixture of two aerosol types (anthropogenic and maritime) from ATSR-2 data. The nadir and forward views are used independently, and a comparison between the two views can be used as a consistency check. The study noted that errors in the TOA reflectance arising from an incorrect wind speed could lead to errors of 0.04-0.16 in nadir-view-derived AOD. As typical open ocean optical depths may be of this order (Smirnov et al., 2009), this is a significant possible error source. More recently, this algorithm has been applied by Bennouna et al. (2009) to Spinning Enhanced Visible and Infra-Red Imager (SEVIRI) data. A previous version of the algorithm described here and applied to ATSR-2 data, involv- ing a nadir-view aerosol retrieval algorithm, is detailed by Thomas et al. (2009b) and Thomas et al. (2010). This took a similar approach for sea surface reflectance although allowed the absolute magnitude to vary (while fixing the spectral shape of the surface).

Two-channel aerosol retrieval algorithms are presented for AVHRR by Higurashi and Nakajima (1999) and Mishchenko et al. (1999): these use fixed glint-based surface reflectances calculated as described in Nakajima and Tanaka (1983) and Mishchenko and Travis (1997), respectively. They also consider the impacts of the simple reflectance model on the retrieved AOD and Ångstrom exponent, noting that it can be significant for cases of high wind or pigment concentrations, or low aerosol loadings.

Dedicated ocean colour sensors such as the Sea-viewing Wide Field-of-view Sensor (SeaWiFS) focus on the retrieval of parameters such as chlorophyll- $a$ concentration and treat aerosol as part of an atmospheric correction term. Approximations made in surface reflectance models, such as the "black pixel approximation" (that the water-leaving radiance in the nIR is negligible), have been shown to negatively impact upon the quality of retrieved ocean colour parameters (Siegel et al., 2000). Sano (2004) describes an algorithm for retrieval of AOD, Ångstrom exponent and aerosol refractive index from POLDER reflectance and polarisation measurements at $670 \mathrm{~nm}$ and $865 \mathrm{~nm}$, making use of the black pixel approximation along with the glint formulation of Cox and Munk (1954a).

This work describes a new algorithm for the calculation of sea surface reflectance, drawing upon the methodology of Koepke (1984). The intended application is as part of the Oxford-RAL Aerosol and Clouds (ORAC) scheme. This is discussed here in the context of aerosol retrievals, although the model may also be applied in the case of opticallythin cloud (where the surface contribution at TOA is nonnegligible). As each sensor is different, previous assumptions must be reevaluated, and more recent work taken into account, to create a model suitable for the ATSRs. By modelling accurately the contributions from different sources, retrievals are possible within the sun-glint region, which increases the possible coverage of aerosol retrievals as compared to existing algorithms. Additionally, potential biases in the retrieved aerosol fields arising from neglect of accounting for foam and underlight are avoided, and all four of the visible/nIR channels on the ATSRs may be used. Furthermore, in ORAC, unlike many previously-described algorithms, the surface reflectance is not fixed, adding some flexibility in those cases in which the assumed surface reflectance is incorrect. 


\section{Overview of the ORAC-(A)ATSR aerosol retrieval}

\subsection{The (A)ATSR instruments}

The ATSR series consists of three instruments: ATSR-1 (aboard ERS-1), launched in 1991, ATSR-2 (aboard ERS-2), launched in 1995, and the Advanced ATSR (AATSR, aboard Envisat), launched in 2002. The ATSRs were primarily designed for measurement of sea surface temperature (Závody et al., 1995). While ATSR-1 measured radiance at one wavelength in the near-infrared and three in the thermal infrared part of the spectrum, ATSR-2 and AATSR have an additional three channels in the visible region. It is these visible channels which are key to the instruments' ability to provide data suitable for aerosol retrievals, and so ATSR-2 and AATSR, referred to from here as (A)ATSR, are considered here.

ERS-2 and Envisat are in Sun-synchronous polar orbit with a mean local solar equatorial crossing time of 10:30 a.m. (ERS-2) or 10:00 a.m. (Envisat) for the descending node. The ATSR instruments are unique in that they use two views (near-simultaneous in time) with differing path lengths to discriminate between radiance from the surface and radiance from the atmosphere. (A)ATSR measures at seven channels in the visible and infrared; at present the first four (centred near $550 \mathrm{~nm}, 660 \mathrm{~nm}, 870 \mathrm{~nm}$ and $1.6 \mu \mathrm{m}$, known as channels $1-4$, respectively) are used in the aerosol retrieval scheme. The additional bands are centred near $3.7 \mu \mathrm{m}, 11 \mu \mathrm{m}$ and $12 \mu \mathrm{m}$.

The shortwave quantity reported by (A)ATSR for a given channel is an approximation of the spectral bidirectional reflection factor, the Sun-normalised radiance, $R_{\mathrm{TOA}}\left(\theta_{\mathrm{s}}, \phi_{\mathrm{s}} ; \theta_{\mathrm{v}}, \phi_{\mathrm{v}}\right)$, which is defined

$R_{\mathrm{TOA}}\left(\theta_{\mathrm{s}}, \phi_{\mathrm{s}} ; \theta_{\mathrm{v}}, \phi_{\mathrm{v}}\right)=\frac{\int_{\lambda_{1}}^{\lambda_{2}} \pi L_{\lambda}^{r} \varrho(\lambda) d \lambda}{\int_{\lambda_{1}}^{\lambda_{2}} \cos \theta_{\mathrm{s}} E_{\lambda}^{i} \varrho(\lambda) d \lambda}$

where $\theta_{\mathrm{s}}, \phi_{\mathrm{s}}$ denote the illumination (solar) zenith and azimuth angles and $\theta_{\mathrm{v}}, \phi_{\mathrm{v}}$ the corresponding angles of view (the sensor), respectively. A channel is defined between wavelengths $\lambda_{1}, \lambda_{2}$ to have response $\varrho(\lambda)$. Finally $L_{\lambda}^{r}$ is the radiance measured by the instrument and $E_{\lambda}^{i}$ is the TOA downward solar irradiance.

The area sampled by (A)ATSR consists of two curved swathes: a nadir view, looking down at zenith angles from $0^{\circ}-22^{\circ}$, and a forward view inclined between $53^{\circ}-55^{\circ}$ to the normal to the surface. There are 555 pixels across the nadir swath (with a size of about $1 \mathrm{~km}^{2}$ at the centre) and 371 across the forward swath (with a size of about $1.5 \mathrm{~km}^{2}$ at the centre). During each scan cycle the satellite moves approximately $1 \mathrm{~km}$ onward with respect to the Earth's surface; after around $150 \mathrm{~s}$ the satellite has moved such that nadir view samples the same region, giving two views of the scene with differing path lengths. Global coverage is achieved every 3-6 days depending on location. ATSR-2 operates in a narrow-swath mode over much of the ocean, reducing coverage by approximately half, due to data-downlinking restrictions from the ERS-2 platform.

(A)ATSR has an on-board visible calibration system consisting of an opal diffuser which views the Sun once per orbit. This, together with vicarious calibration against stable bright ground targets, means that the visible channel reflectances are known to an accuracy of 2-3\% (Smith et al., 2002, 2008).

\subsection{The ORAC retrieval}

ORAC is an optimal estimation (OE) retrieval (Rodgers, 2000) making use of Levenburg-Marquardt iteration (Levenberg, 1944; Marquardt, 1963) to find the most probable state of the surface and atmosphere given measurements and a priori information. The measurement vector consists of the TOA reflectances for the nadir and forward views of the first four channels. The retrieved state parameters (the "state vector") are the aerosol optical depth at $550 \mathrm{~nm}\left(\tau_{550}\right)$, the aerosol effective radius $\left(r_{\mathrm{e}}\right)$ and the surface bihemispherical reflectance at each of the four channels used $\left(R_{\mathrm{dd}, 1}, R_{\mathrm{dd}, 2}\right.$, $R_{\mathrm{dd}, 3}$ and $\left.R_{\mathrm{dd}, 4}\right)$. The AOD is reported at $550 \mathrm{~nm}$ as this is the commonly-used standard; the derived AOD may, however, be referenced to any wavelength, and is obtained from all measurements simultaneously.

For computational speed, cloud-free forward and nadirview data are typically averaged to a $10 \mathrm{~km}$ sinusoidal grid before the ORAC retrieval is performed. This averaging to a coarser resolution is known as "superpixelling". From here, the term "ground scene" is taken to refer to the data, superpixelled or not, used for an individual retrieval. However, ORAC can in principle be performed at any resolution.

The robust statistical basis of $\mathrm{OE}$ provides the following advantages:

1. Estimates of the quality of the retrieval solution (the retrieval "cost") for each ground scene. This is essentially an error-weighted $\chi^{2}$ test of the fit to the measurements at the retrieval solution, which provides a level of confidence as to the results of any one retrieval.

2. Estimates of the random error on each retrieved parameter for each ground scene. These arise through knowledge of the uncertainty on the measurements and any a priori data, propagated through the forward model.

3. The ability (but not requirement) to use any a priori data available on the state parameters. The model described in this work provides an a priori for the surface bihemispherical reflectance.

The retrieval forward model, presented in Thomas et al. (2009a), calculates the TOA reflectance for a given viewing geometry and state vector. It makes use of precalculated lookup tables (LUTs) of atmospheric transmission and reflectance using the DISORT radiative transfer code (Stamnes et al., 1988). A selection of aerosol models are used in the 
retrieval, corresponding to typical continental, desert, maritime or urban aerosol, using aerosol components drawn from the OPAC database of Hess et al. (1998), and additionally a model for biomass burning aerosol drawn from Dubovik et al. (2002). These models consist of mixtures of aerosol components, and different effective radii are obtained by altering their mixing ratios during the retrieval. Generally, the retrieval is attempted for each aerosol type. The most likely aerosol type may be chosen either by considering the model which resulted in the best fit to the measurements (the lowest retrieval cost), or using other available information external to the retrieval.

\subsection{Surface reflectance in the ORAC forward model}

Schaepman-Strub et al. (2006) noted that in remote sensing terms relating to reflectance were often misunderstood or applied ambiguously or incorrectly. They defined nomenclature for nine types of reflectance, using the framework of Nicodemus et al. (1977), corresponding to incoming and outgoing radiation that is either directional, conical or hemispherical. The relevant geometric notation used throughout this work is given in Table 1. For clarity and conciseness of notation, spectral variability of the reflectances is implicit in the definitions and so omitted in the notation.

The most fundamental quantity is the bidirectional reflectance distribution function (BRDF), denoted in the ORAC retrieval by $R_{\mathrm{bb}}$ :

$R_{\mathrm{bb}}\left(\theta_{\mathrm{s}}, \phi_{\mathrm{s}} ; \theta_{\mathrm{v}}, \phi_{\mathrm{v}}\right)=\frac{\partial L_{\lambda}^{r}\left(\theta_{\mathrm{s}}, \phi_{\mathrm{s}} ; \theta_{\mathrm{v}}, \phi_{\mathrm{v}}\right)}{\partial E_{\lambda}^{i}\left(\theta_{\mathrm{s}}, \phi_{\mathrm{s}}\right)}$

This defines the BRDF in terms of the proportion $L_{\mathrm{r}}$ of the incident irradiance $E_{\mathrm{i}}$ reflected from direction $\left(\theta_{\mathrm{S}}, \phi_{\mathrm{S}}\right)$ into direction $\left(\theta_{\mathrm{v}}, \phi_{\mathrm{v}}\right)$. In this case, the point of incidence is the Sun and point of reflection is the satellite sensor. It has units of $\mathrm{sr}^{-1}$, and as a ratio of infinitesimal quantities it (and other directional reflectances) may not be directly observed. In general use the term is defined as a surface property, although a TOA BRDF could also be defined as a conceptual analogue to $R_{\mathrm{TOA}}$. The $\mathrm{BRDF}$ is integrable over angles to obtain the other reflectance quantities given by Schaepman-Strub et al. (2006). Unitless reflectance factors are defined as the ratio of observed radiant flux to the radiant flux reflected under the same geometric conditions by an ideal Lambertian surface, such that the bidirectional reflectance factor (BRF) is the BRDF multiplied by $\pi$ (Schaepman-Strub et al., 2006).

The closest observable equivalent to the BRF is the biconical (or conical-conical) reflectance factor (BCRF or CCRF), obtained by integrating the BRF over solid angles $\omega$ to generate cones of incident and reflected light. Conical quantities become a good approximation for the related directional qualities when the solid angles of the cones are small. In this case the solid angle subtended by the Sun is small, as is the instrument's instantaneous field of view (IFOV) of 1/777 rad.
Table 1. Geometric notation relating to reflectance used in this work.

\begin{tabular}{cl}
\hline Symbol & Meaning \\
\hline$\theta_{\mathrm{S}}$ & Solar zenith angle (measured from vertical) \\
$\phi_{\mathrm{S}}$ & Solar azimuth angle (measured from north) \\
$\theta_{\mathrm{V}}$ & Viewing zenith angle (measured from vertical) \\
$\phi_{\mathrm{V}}$ & Viewing azimuth angle (measured from north) \\
$\phi_{\mathrm{r}}$ & Relative azimuth angle, $\phi_{\mathrm{S}}-\phi_{\mathrm{V}}$ \\
$\phi_{\mathrm{W}}$ & Wind azimuth angle (measured from north) \\
$\chi_{\mathrm{w}}$ & Relative wind direction, $\phi_{\mathrm{S}}-\phi_{\mathrm{W}}$ \\
$\omega$ & Direction pair $(\theta, \phi)$ in spherical coordinates \\
\hline
\end{tabular}

For ambient lighting conditions there will be atmospheric contributions from diffusely-scattered light and absorption. These effects lead to the need for an "atmospheric correction" for ground-based sensing applications, or conversely they provide the "signal" for atmospheric sounding; i.e. the biconical reflectance observed at the TOA may have significantly different spectral and angular characteristics to the biconical reflectance just above the surface. Through optimal estimation, ORAC extracts the information about both from the TOA measurements.

To account for the mixture of direct and diffuse illumination the ORAC retrieval forward model (Thomas et al. , 2009a) treats the direct and diffuse contributions to TOA reflectance with separate terms, subjecting them to different reflectances at ground, and different atmospheric transmittances. The surface reflectances required for direct and diffuse radiance may be derived from the BRDF. Hence it becomes necessary to define three types of surface reflectance in the forward model:

1. The surface BRDF, $R_{\mathrm{bb}}$. This describes the reflection of the direct solar beam into the viewing angle, and is a function of both solar and viewing angles. The BRDF is different for each of AATSR's viewing geometries. This is assumed equivalent to the CCRDF and so no integration over solid angle is performed.

2. The directional-hemispherical reflectance (DHR), $R_{\mathrm{bd}}$. This describes the diffuse reflection of the direct beam over the whole hemisphere (or alternatively direct reflection of incoming diffuse radiance), and is a function of the solar angle. The short time delay between the forward and nadir views means that the solar angle and hence DHR are effectively identical for both views. This is sometimes referred to as black-sky albedo, as incoming illumination comes from a sole direction. 
3. The bihemispherical reflectance (BHR), $R_{\mathrm{dd}}$. This describes the reflection of diffuse downwelling radiation, assumed isotropic. Hence it is independent of the geometry, and is the quantity retrieved by the retrieval algorithm. This is sometimes referred to as white-sky albedo, as illumination arises from the whole of the sky.

In this notation the subscript $\mathrm{b}$ indicates a direct beam reflectance and d a diffuse reflectance; the DHR $R_{\mathrm{bd}}$, for example, denotes an incoming direct beam being diffusely reflected. Given an analytical description of $R_{\mathrm{bb}}$, the DHR for a given solar zenith angle may be obtained by integration over all satellite viewing zenith and relative (solar-satellite) azimuth angles:

$$
\begin{aligned}
R_{\mathrm{bd}}\left(\theta_{\mathrm{s}}\right)= & \frac{\int_{0}^{2 \pi} \int_{0}^{\pi / 2} R_{\mathrm{bb}}\left(\theta_{\mathrm{s}}, \phi_{\mathrm{s}} ; \theta_{\mathrm{v}}, \phi_{\mathrm{v}}\right) \cos \theta_{\mathrm{v}} \sin \theta_{\mathrm{v}} d \theta_{\mathrm{v}} d \phi_{\mathrm{r}}}{\int_{0}^{2 \pi} \int_{0}^{\pi / 2} \cos \theta_{\mathrm{v}} \sin \theta_{\mathrm{v}} d \theta_{\mathrm{v}} d \phi_{\mathrm{r}}} \\
& =\frac{1}{\pi} \int_{0}^{2 \pi} \int_{0}^{\pi / 2} R_{\mathrm{bb}}\left(\theta_{\mathrm{s}}, \phi_{\mathrm{s}} ; \theta_{\mathrm{v}}, \phi_{\mathrm{v}}\right) \cos \theta_{\mathrm{v}} \sin \theta_{\mathrm{v}} d \theta_{\mathrm{v}} d \phi_{\mathrm{r}}
\end{aligned}
$$

This may then be integrated over all solar zenith angles to obtain the BHR:

$$
\begin{aligned}
R_{\mathrm{dd}} & =\frac{\int_{0}^{\pi / 2} R_{\mathrm{bd}}\left(\theta_{\mathrm{s}}\right) \cos \theta_{\mathrm{s}} \sin \theta_{\mathrm{s}} d \theta_{\mathrm{s}}}{\int_{0}^{\pi / 2} \cos \theta_{\mathrm{s}} \sin \theta_{\mathrm{s}} d \theta_{\mathrm{s}}} \\
& =2 \int_{0}^{\pi / 2} R_{\mathrm{bd}}\left(\theta_{\mathrm{s}}\right) \cos \theta_{\mathrm{s}} \sin \theta_{\mathrm{s}} d \theta_{\mathrm{s}}
\end{aligned}
$$

For the ocean surface, Gaussian quadrature integration with 4 points in each angular dimension is sufficient to obtain the DHR and BHR to 3 significant figures from the BRDF (the glint contribution is precalculated with a higher number of points, as discussed later). The BHR at each wavelength used are retrieved by the ORAC scheme, but there is insufficient information to also retrieve the full BRDF from the measurements. Therefore BRDF models are used to generate $R_{\mathrm{bb}}, R_{\mathrm{bd}}$ and the a priori $R_{\mathrm{dd}}$. The ratios $R_{\mathrm{bb}}: R_{\mathrm{dd}}$ and $R_{\mathrm{bb}}: R_{\mathrm{bd}}$ are fixed in the aerosol retrieval, such that when $R_{\mathrm{dd}}$ is scaled in an iterative step in the retrieval then these ratios are used to scale $R_{\mathrm{bb}}$ and $R_{\mathrm{bd}}$ by the corresponding factor. This work describes the sea surface BRDF as calculated in ORAC.

\section{The three components of $R_{b b}$}

The model described in this work draws on the heritage of Koepke (1984). An implementation of the Koepke (1984) description of surface reflectance, focusing on the $400 \mathrm{~nm}-$ $700 \mathrm{~nm}$ spectral range, is in the $6 \mathrm{~S}$ radiative transfer code described by Vermote et al. (1997). Koepke (1984) describes $R_{\mathrm{bb}}$ as being composed of three terms representing different sources of upwelling irradiance. Firstly, light can be reflected off whitecaps in the rough ocean surface; secondly, it can be $[\mathrm{t}]$

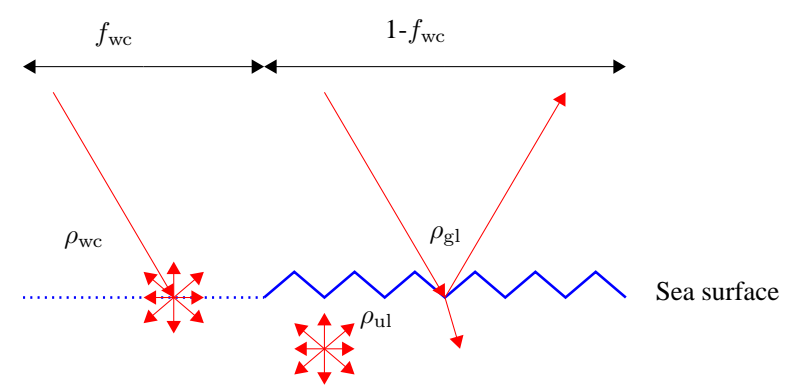

Sea floor

Fig. 1. Schematic representation of the sea surface BRDF model. Blue lines indicate the sea surface (dotted the whitecap-covered portion, and solid the wind-ruffled surface from which the glint reflectance arises), and red light rays.

Table 2. Spectral and directional variability of components of $R_{\mathrm{bb}}$.

\begin{tabular}{lll}
\hline $\begin{array}{l}\text { Contribution } \\
\text { from }\end{array}$ & $\begin{array}{l}\text { Spectral } \\
\text { variability }\end{array}$ & $\begin{array}{l}\text { Directional } \\
\text { variability }\end{array}$ \\
\hline Whitecaps & Moderate & None \\
Glint & Weak & Strong \\
Underlight & Strong & Weak \\
\hline
\end{tabular}

reflected off the foam-free portion of the surface. The contributions from these two factors will depend on the roughness of the sea surface, which is determined by the wind speed. Thirdly, light penetrating the surface can be scattered back up into the atmosphere by molecules within the body of water. The combination of these terms leads to the relationship

$R_{\mathrm{bb}}=f_{\mathrm{wc}} \rho_{\mathrm{wc}}+\left(1-f_{\mathrm{wc}}\right)\left(\rho_{\mathrm{gl}}+\rho_{\mathrm{ul}}\right)$

where $f_{\mathrm{wc}} \rho_{\mathrm{wc}}$ is the contribution to reflectance from whitecaps; $\rho_{\mathrm{gl}}$ represents the sun glint; and $\rho_{\mathrm{ul}}$ denotes the "underlight" term from radiance reflected just below the surface of the water. This is represented schematically in Fig. 1. Although these components represent reflectances, they are denoted using $\rho$ instead of $R$ for clarity. These three components are dealt with individually due to their differing directional and spectral variability, as summarised in Table 2 . The terms $\rho_{\mathrm{gl}}$ and $\rho_{\mathrm{ul}}$ are weighted against by a factor of $\left(1-f_{\mathrm{wc}}\right)$, where $f_{\mathrm{wc}}$ is the fractional cover of whitecaps, as specular reflectance and underlight are taken to arise from only the foam-free portion of the surface. The formulation for $\rho_{\mathrm{ul}}$ includes a correction to account for light lost due to glint reflection at the surface (see Sect. 6). 


\section{Whitecaps}

Whitecaps are where the ocean appears bright due to the action of wind creating a foam. The simplest of the three components of $R_{\mathrm{bb}}$, their only dependence is on wind speed and wavelength. The contribution of whitecaps to reflectance is the product of the proportion of the surface covered by whitecaps $\left(f_{\mathrm{wc}}\right)$ and their average reflectance $\left(\rho_{\mathrm{wc}}\right)$. Koepke (1984) treated whitecap reflectance in the visible region as constant with wavelength, although noted that in the nearinfrared it might be expected to decrease due to absorption by water molecules. More recent coastal (Frouin et al., 1996) and open ocean (Nicolas et al., 2001) work suggests a reflectance of about 0.4 at shorter wavelengths, decreasing by about $40 \%$ at $850 \mathrm{~nm}$ and $85 \%$ at $1.65 \mu \mathrm{m}$. These ratios have been adopted here for use at the nearby (A)ATSR channels, with reflectance at $550 \mathrm{~nm}$ and $660 \mathrm{~nm}$ assumed equal to 0.4 .

Kokhanovsky (2004) develops a physical model for whitecap reflectance, which is then parametrised in terms of the (spectral) water absorption and a spectrally neutral coefficient. This coefficient is determined on a case-by-case basis from several measurement sets, including Frouin et al. (1996). This model suggests that the whitecap reflectance may vary globally. The adoption of global values based on Frouin et al. (1996) and Nicolas et al. (2001) introduces in most cases negligible error into the calculation of $R_{\mathrm{bb}}$ as the whitecap fraction is generally low, and the variability among the experimental cases studied in Kokhanovsky (2004) is small compared to uncertainties in the whitecap reflectance (Frouin et al., 1996; Nicolas et al., 2001) and whitecap fraction.

The whitecap fraction is here parameterised in terms of wind speed, $w$, by a simple power law according to the method of Monahan and Muircheartaigh (1980). The fractional cover of whitecaps is given by

$f_{\mathrm{wc}}=2.951 \times 10^{-6} w^{3.52}$

with the caveat that $f_{\mathrm{wc}}$ cannot be greater than 1 . It should be noted that determination of $f_{\mathrm{wc}}$ is complicated and various formulations based on wind speed and other environmental factors have been developed. An overview of some of these methods is given by Anguelova and Webster (2006). The method of Monahan and Muircheartaigh (1980) is used as it has been widely adopted (such as Koepke, 1984) and requires only easily-available wind speed data. In the ORAC retrieval scheme, 6-hourly $10 \mathrm{~m}$ winds at 1 degree resolution from the European Centre for Medium-range Weather Forecasts (ECMWF), linearly interpolated in space and time, are used throughout.

The contribution of whitecap reflectance to $R_{\mathrm{bb}}$ as a function of wind speed is shown in Fig. 2. As it lacks geometric dependence, the contribution of whitecaps to $R_{\mathrm{bb}}, R_{\mathrm{bd}}$ and $R_{\mathrm{dd}}$ are the same. The global mean wind speed for 2004, sampled at AATSR overpass times, is shown in Fig. 3. For wind speeds of approximately $10 \mathrm{~ms}^{-1}$ and higher $f_{\mathrm{wc}}$

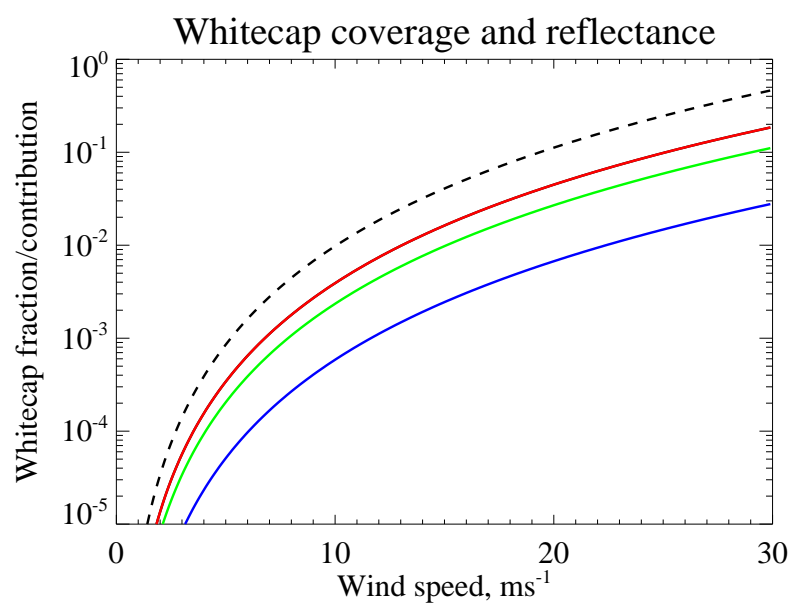

Fig. 2. Whitecap coverage and contribution to the BRDF as a function of wind speed. The dashed black line indicates the whitecap coverage $f_{\mathrm{wc}}$. The red line shows the contribution $f_{\mathrm{wc}} \rho_{\mathrm{wc}}$ to $R_{\mathrm{bb}}$ at $550 \mathrm{~nm}$ and $660 \mathrm{~nm}$, the green line the contribution at $870 \mathrm{~nm}$, and the blue line the contribution at $1.6 \mu \mathrm{m}$.

and $f_{\mathrm{wc}} \rho_{\mathrm{wc}}$ are considerable $\left(10^{-3}-10^{-2}\right.$, except at $\left.1.6 \mu \mathrm{m}\right)$. Such high wind speeds are found polewards of $45^{\circ}$, with typical ocean wind speeds elsewhere in the range $5-8 \mathrm{~ms}^{-1}$, corresponding to $\rho_{\mathrm{wc}}$ around $10^{-4}-10^{-3}$.

There are several sources of uncertainty with this section of the algorithm:

- There is a large uncertainty of up to $50 \%$ in the spectral reflectance of whitecaps (Frouin et al., 1996; Nicolas et al., 2001; Kokhanovsky, 2004).

- Anguelova and Webster (2006) reveal that different parameterisations of $f_{\mathrm{wc}}$ can lead to estimates differing by up to an order of magnitude, as a simple dependence on wind speed is inadequate to explain observed variability. This may be a significant source of error in high-wind or low-chlorophyll environments away from the sun-glint region.

\section{Glint reflectance}

The contribution $\rho_{\mathrm{gl}}$ results from rays of light striking the wind-ruffled sea surface and being specularly reflected in the observer's direction. It is calculated using the model of Cox and Munk (1954a) and Cox and Munk (1954b), from which key equations are reproduced here for completeness. More complicated than whitecaps, glint depends strongly on geometry, wind speed and wind direction, and weakly on wavelength. 


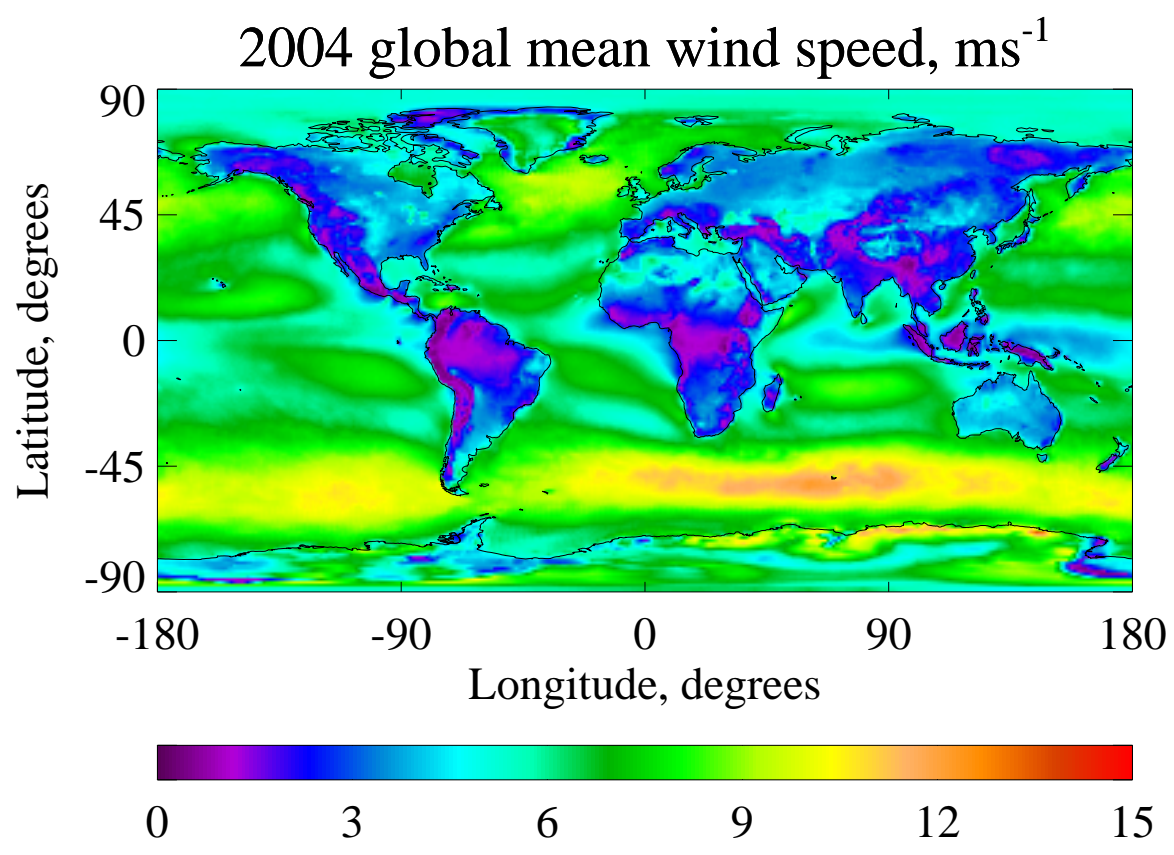

Fig. 3. Global mean near-surface wind speed from ECMWF for the year 2004, sampled at AATSR overpass times.

\subsection{Calculation}

The algorithm defines a coordinate system $(P, X, Y, Z)$ such that $P$ is the observed point on the surface and $Z$ the altitude with $P Y$ in the direction of the Sun and $P X$ in the direction perpendicular to the Sun's plane. The surface slope is defined by the two components

$Z_{\mathrm{x}}=\frac{\partial Z}{\partial X}=\frac{-\sin \theta_{\mathrm{v}} \sin \phi}{\cos \theta_{\mathrm{s}}+\cos \theta_{\mathrm{V}}}$

$Z_{\mathrm{y}}=\frac{\partial Z}{\partial Y}=\frac{\sin \theta_{\mathrm{s}}+\sin \theta_{\mathrm{v}} \cos \phi}{\cos \theta_{\mathrm{s}}+\cos \theta_{\mathrm{v}}}$

where $\theta_{\mathrm{s}}<\pi / 2$ and $\theta_{\mathrm{v}}>0$. In reality, the slope distribution will be anisotropic and dependent on wind direction $\chi_{w}$. The axes are rotated clockwise from the north by $\chi_{\mathrm{w}}$ to define a new coordinate system $\left(P, X^{\prime}, Y^{\prime}, Z\right)$ where $P Y^{\prime}$ is parallel to the wind direction, and where the slope components may be re-expressed:

$Z_{\mathrm{x}}^{\prime}=\cos \left(\chi_{\mathrm{w}}\right) Z_{\mathrm{x}}+\sin \left(\chi_{\mathrm{w}}\right) Z_{\mathrm{y}}$

$Z_{\mathrm{y}}^{\prime}=-\sin \left(\chi_{\mathrm{w}}\right) Z_{\mathrm{x}}+\cos \left(\chi_{\mathrm{w}}\right) Z_{\mathrm{y}}$

Following Cox and Munk (1954a), the probability distribution of surface facets $p\left(Z_{\mathrm{x}}^{\prime}, Z_{\mathrm{y}}^{\prime}\right)$ is required to calculate the glint reflectance. The original work provided coefficients for 3 parametrisations for $p$ :

- Wind-isotropic (dependent only on absolute wind speed).
- Wind-anisotropic (dependent on upwind and crosswind wind speed).

- Wind-anisotropic, with an additional Gram-Charlier series correction term.

Recently, Zhang and Wang (2009) evaluated these parametrisations, along with other work drawing on the heritage of Cox and Munk (1954a) (specifically Wu, 1972; Mermelstein et al., 1994; Shaw and Churnside, 1997; Shifrin, 2001; Ebuchi and Kizu, 2002, and Bréon and Henriot, 2006) using MODIS measurements. It was found that the anisotropic model (without the Gram-Charlier series) of Cox and Munk (1954a), and the model of Bréon and Henriot (2006), were very similar and provided the best model for the observed glint. The conclusions remain valid for (A)ATSR as it has similar channels to MODIS. Therefore the anisotropic model of Cox and Munk (1954a) is adopted here; the resulting expression for the slope distribution is

$p\left(Z_{\mathrm{x}}^{\prime}, Z_{\mathrm{y}}^{\prime}\right)=\frac{1}{2 \pi \sigma_{\mathrm{x}}^{\prime} \sigma_{\mathrm{y}}^{\prime}} e^{\left(-\frac{\zeta^{2}+\eta^{2}}{2}\right)}$

where the terms $\zeta=Z_{\mathrm{x}}^{\prime} / \sigma_{\mathrm{x}}^{\prime}$ and $\eta=Z_{\mathrm{y}}^{\prime} / \sigma_{\mathrm{y}}^{\prime}$, and $\sigma_{\mathrm{x}}^{\prime}$ and $\sigma_{\mathrm{y}}^{\prime}$ are the root mean square values of $Z_{\mathrm{x}}^{\prime}$ and $Z_{\mathrm{y}}^{\prime}$, respectively. The values $\sigma_{\mathrm{x}}^{\prime 2}$, taken as as $0.003+0.00192 \mathrm{w} \pm 0.002$, and $\sigma_{\mathrm{y}}^{\prime 2}$, taken as $0.00316 \mathrm{w} \pm 0.004$, are from Cox and Munk (1954a) for a clean sea surface.

The total contribution $\rho_{\mathrm{gl}}$ is calculated, following Cox and Munk (1954a), as

$\rho_{\mathrm{gl}}=\frac{\pi p\left(Z_{\mathrm{x}}^{\prime}, Z_{\mathrm{y}}^{\prime}\right) R_{\mathrm{f}}}{4 \cos \theta_{\mathrm{s}} \cos \theta_{\mathrm{v}} \cos ^{4} \beta}$ 
Table 3. Refractive indices $\tilde{n}$ for water at relevant wavelengths. Both real $n$ and imaginary $\kappa$ components are given, although only the real part is used in determining the Fresnel coefficient. Adapted from Hale and Querry (1973) and Quan and Fry (1995).

\begin{tabular}{ccc}
\hline $\begin{array}{c}\text { Wavelength } \\
\lambda\end{array}$ & $\begin{array}{c}\text { Real component } \\
n\end{array}$ & $\begin{array}{c}\text { Imaginary component } \\
\kappa\end{array}$ \\
\hline $550 \mathrm{~nm}$ & 1.341 & $1.96 \times 10^{-9}$ \\
$660 \mathrm{~nm}$ & 1.338 & $2.23 \times 10^{-8}$ \\
$870 \mathrm{~nm}$ & 1.334 & $3.91 \times 10^{-7}$ \\
$1.6 \mu \mathrm{m}$ & 1.323 & $8.55 \times 10^{-5}$ \\
\hline
\end{tabular}

where $R_{\mathrm{f}}$ is the Fresnel reflection coefficient, and $\beta$ the facet tilt

$\cos \beta=\frac{\cos \theta_{\mathrm{s}}+\cos \theta_{\mathrm{v}}}{\sqrt{2+2 \cos 2 \Theta}}$

where the scattering angle $\Theta$ between the incident beam and surface facet is obtained using

$\cos 2 \Theta=\cos \theta_{\mathrm{v}} \cos \theta_{\mathrm{S}}+\sin \theta_{\mathrm{v}} \sin \theta_{\mathrm{s}} \cos \phi_{\mathrm{r}}$

such that $2 \Theta$ is the familiar scattering angle between incident and reflected beams.

Calculation of the Fresnel reflection coefficient $R_{\mathrm{f}}$ requires the real component of the refractive index of air, taken as $n_{\mathrm{a}}=1.00029$ for all wavelengths, and of water $n_{\mathrm{w}}$, shown in Table 3. These were calculated at $550 \mathrm{~nm}$ and $670 \mathrm{~nm}$ using the method of Quan and Fry (1995) assuming a temperature of $15^{\circ} \mathrm{C}$ and salinity of 35 parts per thousand, but are correct to four significant figures over the range of typical temperatures and salinities.

This model of Quan and Fry (1995) extends only to $700 \mathrm{~nm}$, so for the longer wavelengths values for pure water from Hale and Querry (1973) were used. At shorter wavelengths there was an offset of around 0.0065 between the refractive index as predicted for pure water and that of salinity typical for the sea, so this adjustment was also applied to the pure water data used at $870 \mathrm{~nm}$ and $1.6 \mu \mathrm{m}$. Values for the imaginary part of the refractive index were likewise taken from Hale and Querry (1973).

For viewing zenith angles more extreme than $70^{\circ}$, a slight modification is made to the denominator of Eq. (12) following Zeisse (1995) to avoid an infinite radiance at viewing zenith angles near the ocean horizon. The reader is referred to Zeisse (1995) for more details; although such extreme viewing geometries do not occur for the (A)ATSR views, calculation of the reflectance at such geometries is required for the integration to obtain $R_{\mathrm{bd}}$ and $R_{\mathrm{dd}}$ for the retrieval forward model.

\subsection{Magnitude of contribution}

The glint contribution $\rho_{\mathrm{gl}}$ to $R_{\mathrm{bb}}$ is shown at $550 \mathrm{~nm}$ in Fig. 4 . The strong geometric dependence is visible; this is key to the ability of (A)ATSR to perform retrievals into the sunglint region, as generally while one view is affected by glint (meaning most signal arises from the surface) the other is not (so most signal arises from the atmosphere). The asymmetry in Fig. 4 arises due to the wind direction not being in line with the field of view. This has a smaller impact as $\theta_{\mathrm{v}}$ tends to the nadir. Dependence on wavelength is weak due to the similarity of the refractive index of water at the modelled wavelengths.

The sea surface BRDF is integrated using Gaussian quadrature with 4 points to obtain $R_{\mathrm{bd}}$ and $R_{\mathrm{dd}}$. The glint contribution requires a large number of points to calculate accurately; as a result precalculated lookup tables (LUTs) of integrated $\rho_{\mathrm{gl}}$, using 360 quadrature points, are used for computational efficiency. These are parametrised in terms of wind speed (for $R_{\mathrm{dd}}$ ) and wind speed and solar zenith angle (for $R_{\mathrm{bd}}$ ). These quantities are shown in Figs. 5 and 6. The glint DHR shows the expected increase with solar zenith angle, and for commonly-encountered conditions is approximately 0.03 (at all wavelengths; shown only for $550 \mathrm{~nm}$ ). For high wind speeds the contribution decreases due to the increased whitecap fraction. The BHR is generally $0.05-0.06$, decreasing as $w$ increases again due to the increase in whitecap fraction. When the whitecap contribution is added, an increase with $w$ is observed (except at $1.6 \mu \mathrm{m}$ where the foam reflectance is small) together with more variability between the wavelengths.

\subsection{Uncertainties}

Over a range of typical conditions, the uncertainties in the coefficients used in the calculation of $p\left(Z_{\mathrm{x}}^{\prime}, Z_{\mathrm{y}}^{\prime}\right)$ (Eq. 11) lead to a variability of around $10 \%$, causing a corresponding uncertainty in $\rho_{\mathrm{gl}}$ of the same amount. This variability decreases at higher wind speeds.

\section{Underlight}

Underlight is upwelling irradiance from just below the surface of the ocean. As such, $\rho_{\mathrm{ul}}$ is influenced strongly by pigment concentration and wavelength, and weakly by geometry. The model described here is designed for Case I waters, following the nomenclature of Morel and Prieur (1977). In Case I waters (typically open ocean) the chlorophyll concentration is high compared to the scattering coefficient; in Case II waters (typically coastal and shallow) scattering by inorganic particles dominates. The semi-empirical relationships between ocean constituents and surface reflectance 

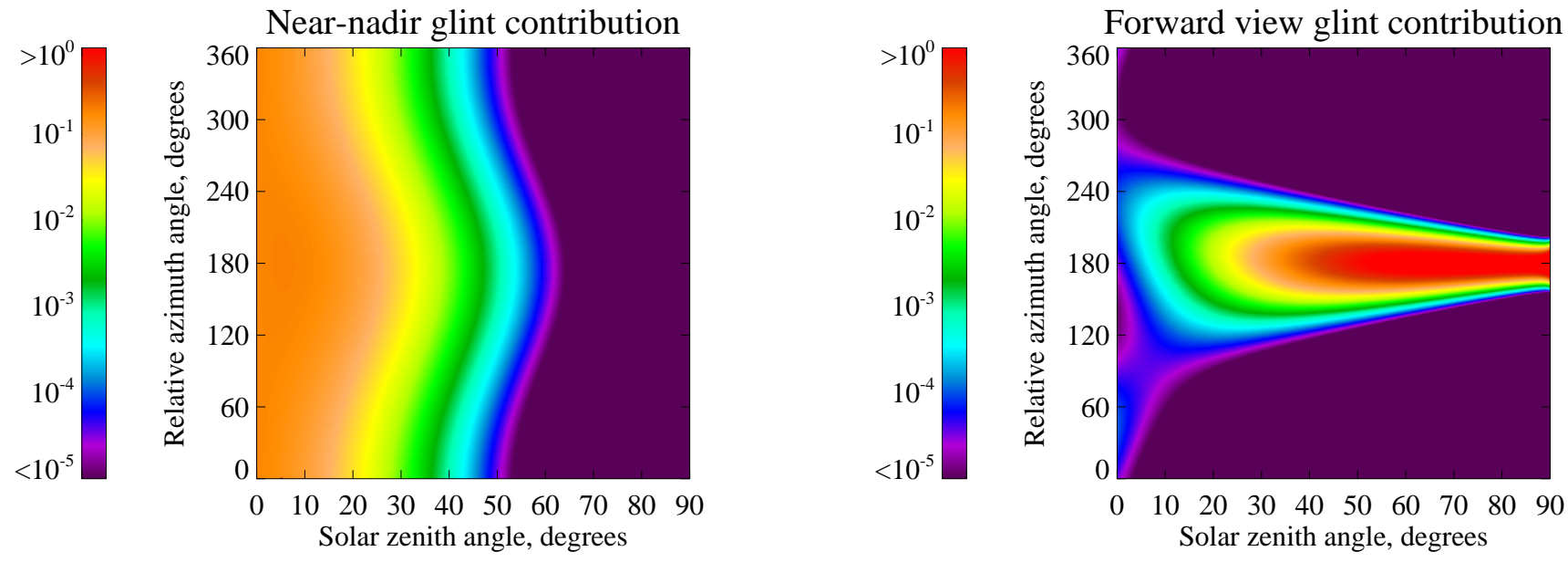

Fig. 4. Glint reflectance $\rho_{\mathrm{gl}}$ at $550 \mathrm{~nm}$ for near-nadir (left, $\theta_{\mathrm{V}}=5^{\circ}$ ) and forward-view (right, $\left.\theta_{\mathrm{V}}=55^{\circ}\right)$ geometries. In both cases $w=5 \mathrm{~ms}{ }^{-1}$ and $\chi_{\mathrm{w}}=135^{\circ}$.

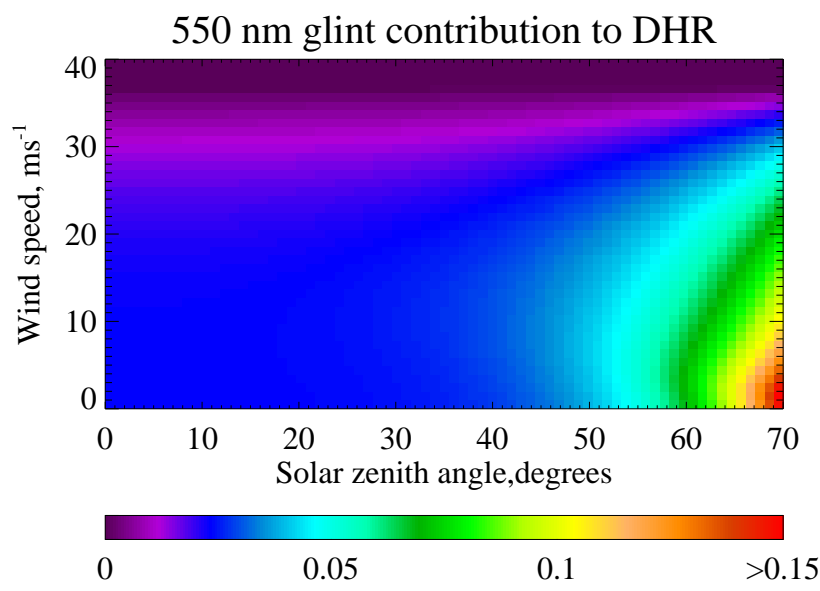

Fig. 5. Glint contribution to the directional-hemispherical reflectance $R_{\mathrm{bd}}$ at $550 \mathrm{~nm}$ as a function of wind speed and solar zenith angle.

developed by Morel and Prieur (1977), Morel and Gentili (1991) and later work are different between Case I and II waters. This work focusses on Case I waters because they cover the majority of the Earth's surface, and scattering in Case II waters is less well-understood.

\subsection{Calculation}

The underlight reflectance is an analogue to the atmospheric scattering problem. Reflectances and transmittances related to underlight are denoted using $\mathcal{R}$ and $\mathcal{T}$, rather than $R$ and $T$, for an easier distinction between other reflectance and transmittance terms used in this work. Fundamentally, the system may be considered to consist of three layers:

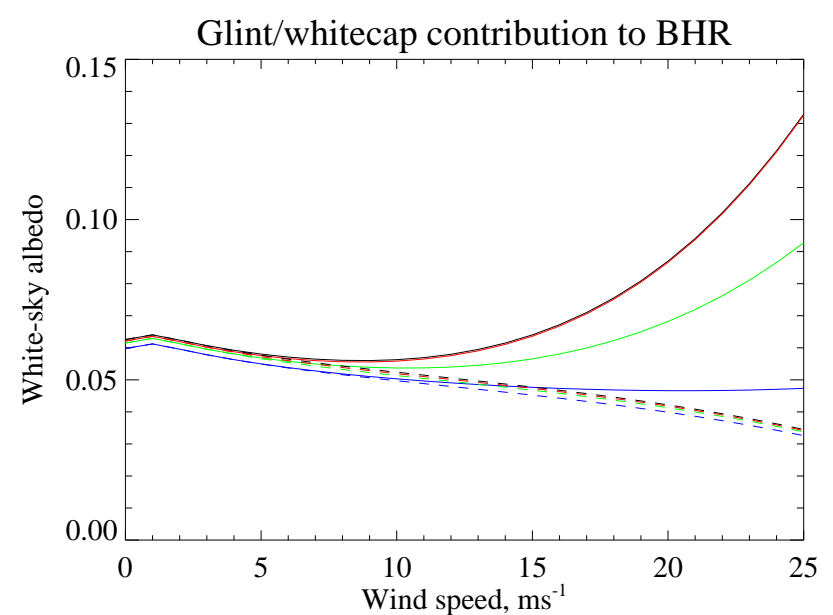

Fig. 6. Glint and whitecap contribution to bihemispherical reflectance $R_{\mathrm{dd}}$ as a function of wind speed. The black lines shows the contribution at $550 \mathrm{~nm}$, red at $660 \mathrm{~nm}$, green at $870 \mathrm{~nm}$, and the blue line the contribution at $1.6 \mu \mathrm{m}$. The dashed lines show the contribution from sun-glint alone, weighted against by the whitecap fraction (Eq. 5), and the solid lines the total contribution from whitecaps and glint.

- The topmost layer, corresponding to the air-water interface. The downward and upward transmittances through this surface are denoted $\mathcal{T}_{\mathrm{d}}$ and $\mathcal{T}_{\mathrm{u}}$, respectively; the (downward) reflectance of upwelling irradiance below the interface is $\mathcal{R}_{\mathrm{u}}$. The upward reflectance of downwelling irradiance above the interface is the glint.

- An "upper ocean" layer, from which the scattered radiation causing the underlight contribution originates. The 
reflectance of this layer is denoted by $\mathcal{R}_{\mathrm{w}}$ and known as the water body reflectance.

- An "ocean floor" layer. This is characterised by the reflectance of the ocean bed, $\mathcal{R}_{\text {bed }}$. The transmittance between the upper layer and ocean floor is denoted $\mathcal{T}_{\mathrm{w}, \mathrm{d}}$ or $\mathcal{T}_{\mathrm{w}, \mathrm{u}}$ for downward and upward directions, respectively.

The problem may be simplified by first considering a combination of the lower two layers. Light penetrating the airwater interface may be reflected back towards it $\left(\mathcal{R}_{\mathrm{w}}\right)$ or subject to multiple "reflections" between the upper ocean and ocean floor. If it is assumed that $\mathcal{R}_{\text {bed }}$ is isotropic then it can be easily shown that the combination of these two layers reduces to

$\mathcal{R}_{\mathrm{w}}+\frac{\mathcal{T}_{\mathrm{w}, \mathrm{d}} \mathcal{R}_{\text {bed }} \mathcal{T}_{\mathrm{w}, \mathrm{u}}}{1-\mathcal{R}_{\mathrm{w}} \mathcal{R}_{\text {bed }}}$

which is the reflectance $\mathcal{R}_{\mathrm{w}}$ of the incident light from the water body, plus a multiple-scattering geometric series limit.

This combination of the two lower layers may then be treated as a single (lower) layer of a two-layer system, in which the upper layer corresponds to the air-water interface. If it is assumed that this lower layer is an isotropic reflector then the same series limit may be applied to this simpler two-layer system to calculate $\rho_{\mathrm{ul}}$ :

$\rho_{\mathrm{ul}}=\frac{\mathcal{T}_{\mathrm{d}}\left(\mathcal{R}_{\mathrm{w}}+\frac{\mathcal{T}_{\mathrm{w}, \mathrm{d}} R_{\mathrm{bed}} \mathcal{T}_{\mathrm{w}, \mathrm{u}}}{1-\mathcal{R}_{\mathrm{w}} \mathcal{R}_{\mathrm{bed}}}\right) \mathcal{T}_{\mathrm{u}}}{1-\mathcal{R}_{\mathrm{u}}\left(\mathcal{R}_{\mathrm{w}}+\frac{\mathcal{T}_{\mathrm{w}, \mathrm{d}} R_{\text {bed }} \mathcal{T}_{\mathrm{w}, \mathrm{u}}}{1-\mathcal{R}_{\mathrm{w}} \mathcal{R}_{\text {bed }}}\right)}$

The geometric dependence of $\mathcal{R}_{\mathrm{w}}$ is weak and its absolute value is small, so the error introduced by this approximation is small. The direct reflectance of incoming light off the interface was dealt with as the sun-glint term and so is not part of Eq. (16). A further approximation may be made to simplify the calculation of $\rho_{\mathrm{ul}}$ for the open ocean. The transmittance $\mathcal{T}_{\mathrm{w}}$ of water (either upward or downward) may be calculated as

$\mathcal{T}_{\mathrm{W}}=e^{-a_{\mathrm{w}} z}$

where $a_{\mathrm{w}}$ is the absorption coefficient of the water, and $z$ the path length (for a vertical column, equal to the depth of the water). For pure water, $a_{\mathrm{w}}$ can be calculated from the complex part of the refractive index:

$a_{\mathrm{w}}=\frac{4 \pi}{\lambda} \kappa$

Using $\kappa$ from Table 3, over all wavelengths of interest, and even in shallow water (with $z=100 \mathrm{~m}$ ), $\mathcal{T}_{\mathrm{w}}$ is very small $\left(10^{-2}\right.$ for $z=100 \mathrm{~m}$ at $550 \mathrm{~nm}$, and orders of magnitude smaller for deeper water or longer wavelengths). Dissolved substances in seawater would further decrease $\mathcal{T}_{\mathrm{w}}$. As a result $\mathcal{T}_{\mathrm{w}, \mathrm{d}} R_{\text {bed }} \mathcal{T}_{\mathrm{w}, \mathrm{u}}$, the proportion of light transmitted through the water, reflected off the bottom and then transmitted up through the water body, is negligible and Eq. (16) may be simplified to

$\rho_{\mathrm{ul}}=\frac{\mathcal{T}_{\mathrm{d}} \mathcal{R}_{\mathrm{w}} \mathcal{T}_{\mathrm{u}}}{1-\mathcal{R}_{\mathrm{u}} \mathcal{R}_{\mathrm{w}}}$

which is the expression used to calculate $\rho_{\mathrm{ul}}$ in this scheme. It is noteworthy that in very shallow waters, or wavelengths at which water is more transparent, the reflectance characteristics of the ocean floor may become important and so Eq. (16) is presented as the general case. An analagous formulation was presented by Austin (1974).

\subsubsection{Downwelling transmittance coefficient, $\mathcal{T}_{\mathrm{d}}$}

The term $\mathcal{T}_{\mathrm{d}}$ in Eq. (19) represents the transmittance of downwelling radiation. Assuming a flat sea surface, this is simply calculated using the Fresnel coefficient for an incident beam of a given solar zenith angle, and noting that light not reflected is transmitted:

$\mathcal{T}_{\mathrm{d}}\left(\theta_{\mathrm{s}}\right)=1-\mathcal{R}_{\mathrm{f}: \mathrm{aw}}\left(\theta_{\mathrm{s}}\right)$

The subscript in $\mathcal{R}_{\text {f:aw }}$ reminds that the incident beam is coming from the air, into the water. For all wavelengths, $\mathcal{T}_{\mathrm{d}}$ is approximately 0.98 for $\theta_{\mathrm{s}}<60^{\circ}$ but drops sharply for larger zenith angles. Calculation for a wind-roughened sea is computationally expensive, as it involves the calculation of the transmittance through all possible facets. Austin (1974) present results for selected angles and wind speeds, and note that for wind-ruffled seas $\mathcal{T}_{\mathrm{d}}$ is slightly lower than 0.98 for near-zenith angles of incidence, and the decline in transmittance is slower as the Sun approaches the horizon, although the changes are not large. Therefore the assumption of a flat sea surface introduces minimal additional error.

\subsubsection{Upwelling transmittance coefficient, $\mathcal{T}_{\mathrm{u}}$}

The transmittance of the underlight through the water-air interface is denoted $\mathcal{T}_{\mathrm{u}}$. If the upwelling irradiance is assumed to be diffuse, and the sea surface flat, then $\mathcal{T}_{\mathrm{u}}$ is given by integrating the Fresnel coefficient over all possible upwelling angles $\theta_{\mathrm{u}}$ :

$\mathcal{T}_{\mathrm{u}}=\frac{\int_{0}^{\pi / 2}\left(1-\mathcal{R}_{\mathrm{f}: \mathrm{wa}}\left(\theta_{\mathrm{u}}\right)\right) \cos \theta_{\mathrm{u}} \sin \theta_{\mathrm{u}} \mathrm{d} \theta_{\mathrm{u}}}{\int_{0}^{\pi / 2} \cos \theta_{\mathrm{u}} \sin \theta_{\mathrm{u}} \mathrm{d} \theta_{\mathrm{u}}}$

Here, $\mathcal{R}_{\text {f:wa }}$ indicates that the upwelling light is travelling from water to air. This gives $\mathcal{T}_{\mathrm{u}}=0.522$ at $550 \mathrm{~nm}, 0.523$ at $660 \mathrm{~nm}, 0.525$ at $870 \mathrm{~nm}$ and 0.536 at $1.6 \mu \mathrm{m}$. These are just over half typical values of $\mathcal{T}_{\mathrm{d}}$ because rays hitting the interface with $\Theta>\sin ^{-1}\left(n_{\mathrm{a}} / n_{\mathrm{w}}\right)$, approximately $48^{\circ}$, are internally reflected so that their energy is lost. Hence the radiance penetrating the surface is limited to the subset with angles of incidence smaller than this critical angle.

As with $\mathcal{T}_{\mathrm{d}}$, for a rough sea calculation becomes more complicated because the transmittance of facets aligned at 
Table 4. Absorption coefficient $a_{\mathrm{w}}\left(\mathrm{m}^{-1}\right)$ for water at AATSR visible channel wavelengths. See Morel and Prieur (1977), Table 3 and Eq. (18).

\begin{tabular}{cc}
\hline $\begin{array}{c}\text { Wavelength } \\
\lambda\end{array}$ & $\begin{array}{c}\text { Absorption coefficient } \\
\text { of water } a_{\mathrm{w}}, \mathrm{m}^{-1}\end{array}$ \\
\hline $550 \mathrm{~nm}$ & 0.064 \\
$660 \mathrm{~nm}$ & 0.410 \\
$870 \mathrm{~nm}$ & 5.65 \\
$1.6 \mu \mathrm{m}$ & 672 \\
\hline
\end{tabular}

different angles to the surface has to be taken into account. Austin (1974) again show, using examples at selected wind speeds and angles, that for increasingly rough seas the transmittance from upwelling rays at near-nadir incidence falls while some transmittance is possible for rays at angles larger than the flat-sea critical angle. The net effect is that $\mathcal{T}_{\mathrm{u}}$ shows little dependence on wind speed, and so the flat-sea assumption is again valid.

\subsubsection{Upwelling reflectance coefficient, $\mathcal{R}_{\mathrm{u}}$}

The final geometric term $\mathcal{R}_{\mathrm{u}}$ is the (downward) reflectance coefficient for upwelling radiance at the water-air boundary. This can be calculated as $1-\mathcal{T}_{\mathrm{u}}$. Austin (1974) give broadband visible values between 0.485 for a still ocean surface and 0.463 for a wind-ruffled surface with $w=16 \mathrm{~ms}^{-1}$; as this dependence on wind speed is small, and $\mathcal{R}_{\mathrm{u}} \mathcal{R}_{\mathrm{w}} \ll 1$, the flat-surface assumption introduces negligible error into Eq. (19).

\subsubsection{Water body reflectance, $\mathcal{R}_{\mathrm{w}}$}

The water body reflectance $\mathcal{R}_{\mathrm{w}}$ is controlled by the optical properties of water and matter within it, and is defined as the ratio of upwelling irradiance from just below the surface to downwelling irradiance just above it. The method of calculation is based on the method of in Morel and Prieur (1977), and further developed on many occasions (e.g. in Morel, 1988 or Morel and Gentili, 1991). The parametrisations are based on a variety of semiempirical relationships. The water body reflectance is calculated from the optical properties of the water as follows:

$$
\mathcal{R}_{\mathrm{W}}=f \frac{b_{\mathrm{b}}(\lambda)}{a(\lambda)}
$$

This describes the colour of the water as the ratio of the total backscattering coefficient $b_{\mathrm{b}}(\lambda)$ to the absorption coefficient $a(\lambda)$, multiplied by some empirical correction factor $f$.

\subsubsection{Absorption coefficient}

A more thorough treatment can be given to the absorption coefficient of water than the approximation made previously. The total absorption coefficient $a$ of seawater can be thought of as the sum of the absorption due to pure water, $a_{\mathrm{w}}$ (as in Eq. 18), that due to phytoplankton pigments $a_{\mathrm{ph}}$, and $a_{\mathrm{CDOM}}$, the absorption due to detritus and coloured dissolved organic matter (CDOM), also known as Gelbstoff:

$a(\lambda)=a_{\mathrm{w}}(\lambda)+a_{\mathrm{ph}}(\lambda)+a_{\mathrm{CDOM}}(\lambda)$

The absorption coefficients used for water are shown in Table 4. Values for $550 \mathrm{~nm}$ and $660 \mathrm{~nm}$ are taken for seawater from Morel and Prieur (1977); for longer wavelengths data are unavailable so at $870 \mathrm{~nm}$ and $1.6 \mu \mathrm{m} a_{\mathrm{w}}$ is estimated using imaginary components of the refractive index from Table 3 with Eq. (18). This approximation is justified as the underlight contribution to $\mathcal{R}_{\mathrm{bb}}$ is small at these wavelengths.

For $a_{\mathrm{ph}}$, the two-component model outlined by Sathyendranath et al. (2001) and Devred et al. (2006) is used. This relates the absorption due to phytoplankton to the concentration $C$ of chlorophyll- $a$ in $\mathrm{mg} \mathrm{m}^{-3}$, assuming a mixed population of two phytoplankton types, by

$a_{\mathrm{ph}}(\lambda)=U\left(1-e^{-S_{\mathrm{chl}} C}\right)+a_{2}^{*}(\lambda) C$

where the parameter $U$ is defined as

$U(\lambda)=C_{1}^{m}\left(a_{1}^{*}(\lambda)-a_{2}^{*}(\lambda)\right)$

where $C_{1}^{m}$ is the maximum chlorophyll- $a$ concentration associated with phytoplankton population 1 in $\mathrm{mg} \mathrm{m}^{-3}$, and $a_{1}^{*}$ and $a_{2}^{*}$ are the specific absorption coefficients in $\mathrm{m}^{-1}$ (mg chl- $a)^{-1}$ of the two populations at the wavelength of interest. $S_{\mathrm{chl}}$ describes the nonlinearity of absorption and has units of $\mathrm{m}^{3}(\mathrm{mg} \operatorname{chl}-a)^{-1}$. For a global dataset, Devred et al. (2006) found $C_{1}^{m}=0.62 \mathrm{mg} \mathrm{m}^{-3}, a_{1}^{*}=0.0109 \mathrm{~m}^{-1}$ (mg chl$a)^{-1}$ at $550 \mathrm{~nm}$ and $0.0173 \mathrm{~m}^{-1}(\mathrm{mg} \mathrm{chl}-a)^{-1}$ at $660 \mathrm{~nm}$, $a_{2}^{*}=0.0064 \mathrm{~m}^{-1}(\mathrm{mg} \mathrm{chl}-a)^{-1}$ at $550 \mathrm{~nm}$ and $0.0085 \mathrm{~m}^{-1}$ $(\mathrm{mg} \mathrm{chl}-a)^{-1}$ at $660 \mathrm{~nm}$, and $S_{\mathrm{chl}}=1.61 \mathrm{~m}^{3}(\mathrm{mg} \mathrm{chl}-a)^{-1}$. Absorption by pigments is neglected at $870 \mathrm{~nm}$ and $1.6 \mu \mathrm{m}$; the very strong absorption of the water at these wavelengths (Table 4) means this approximation has negligible impact. For pigment concentrations of approximately $1 \mathrm{mg} \mathrm{m}^{-3}$ or more $a_{\mathrm{ph}}$ becomes significant at $550 \mathrm{~nm}$ and $660 \mathrm{~nm}$, otherwise it is negligible compared to $a_{\mathrm{w}}$.

Operationally, data for both chlorophyll concentration and CDOM/detritus absorption are obtained from the GlobColour project (Barrot et al., 2006). This provides global values of various ocean colour parameters from merged satellite (MERIS, SeaWIFS and MODIS) datasets. Monthly mean values on an approximately $25 \mathrm{~km} \times 25 \mathrm{~km}$ grid are used, with gaps filled using an annual mean. Figure 7 shows the annual mean pigment (chlorophyll- $a$ and phaeophytin- $a$, normally abbreviated as just "chlorophyll”) concentrations over 2004. 


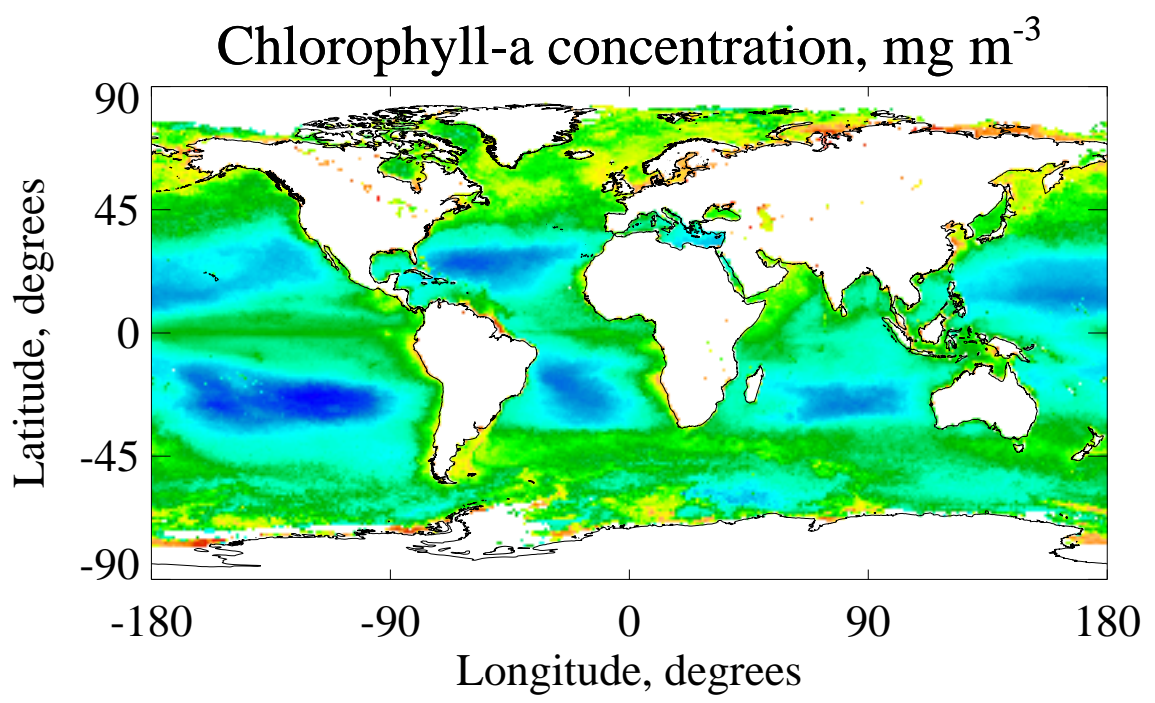

0.01

0.1

1

10

Fig. 7. Annual mean GlobColour-derived chlorophyll- $a$ concentration $\left(\mathrm{mg} \mathrm{m}^{-3}\right)$ for 2004.
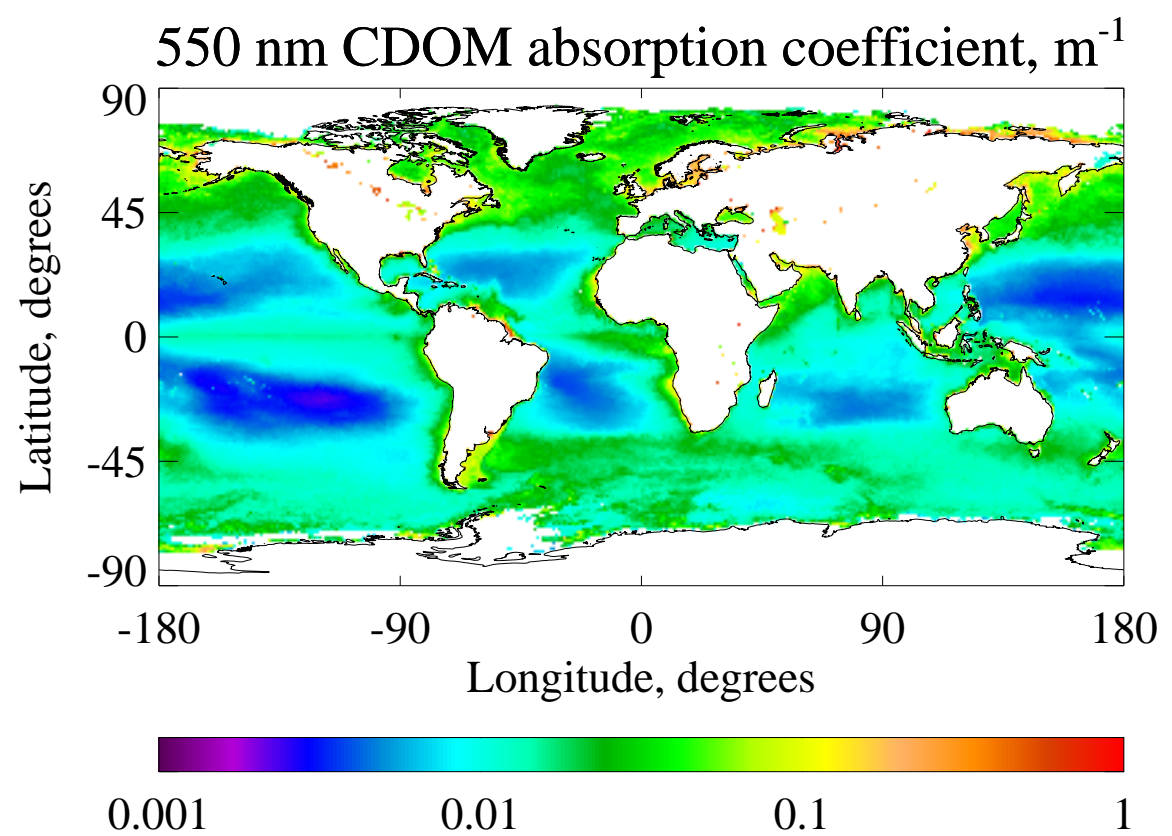

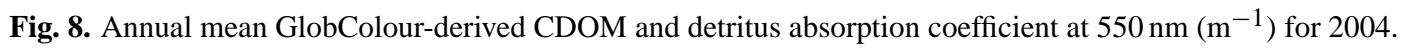

The large spatial variability, as well as range of concentrations spanning several orders of magnitude, is evident. In the open ocean, typical values are in the range 0.05 to $1 \mathrm{mg} \mathrm{m}^{-3}$ but near the coast the concentration can reach $10 \mathrm{mg} \mathrm{m}^{-3}$ or higher. Chlorophyll content is also important for calculating the backscattering coefficient, as discussed in the next section.
Figure 8 presents an analagous map of the annual mean CDOM absorption coefficient at $550 \mathrm{~nm}$ for 2004. According to Roesler et al. (1989), absorption from detritus and CDOM can be treated as one parameter due to their similar spatial distributions and absorption properties; hence, the quantity retrieved by ocean colour algorithms is the total absorption coefficient for both substances. GlobColour provides the 
absorption coefficient at $443 \mathrm{~nm}$ which is related to absorption at longer wavelengths by the following equation:

$a_{\mathrm{CDOM}}(\lambda)=a_{\mathrm{CDOM}}(443) e^{-S(\lambda-443)}$

In Eq. (26) the parameter $S$ describes the spectral slope of the absorption. Roesler et al. (1989) found different values (generally in the range 0.011 to 0.018 ) worked well for different regions of the world, with 0.014 a good value for global studies. This value of 0.014 is used here, as well as assorted other studies (such as Chen et al., 2003).

The CDOM absorption coefficient tends to covary with chlorophyll concentration (Figs. 7 and 8). Typical ocean values at $550 \mathrm{~nm}$ are in the range 0.001 to $0.01 \mathrm{~m}^{-1}$ but again higher values, generally up to $0.1 \mathrm{~m}^{-1}$, can be observed in productive or coastal waters. This algorithm only takes $a_{\mathrm{CDOM}}$ into account at $550 \mathrm{~nm}$. At $660 \mathrm{~nm}$ the value of $S$ means that CDOM absorption is only around a fifth as strong as at $550 \mathrm{~nm}$. Combined with the fact that absorption by water and chlorophyll increases by roughly an order of magnitude, the CDOM contribution to the total absorption coefficient is negligible. At longer wavelengths this effect is even more pronounced. Taking into account the decreasing importance of $\rho_{\mathrm{ul}}$ with increasing wavelength, this approximation has minimal effect on results.

\subsubsection{Backscattering coefficient}

The term $b_{\mathrm{b}}(\lambda)$ is the total backscattering coefficient from molecules and particles. Following Morel and Prieur (1977) this is parameterised as

$b_{\mathrm{b}}(\lambda)=\frac{1}{2} b_{\mathrm{w}}(\lambda)+\tilde{b}_{\mathrm{b}}(\lambda) b$

where $b_{\mathrm{w}}$ is the molecular scattering coefficient for water, and the second term is the product of the particle backscattering probability $\tilde{b}_{\mathrm{b}}$ and particle backscattering coefficient $b$. The division by 2 of $b_{\mathrm{w}}$ arises because molecular scattering is forward-back symmetric, so the backscatter coefficient is half of the molecular scattering coefficient.

Values for $b_{\mathrm{w}}$ for pure water from $380 \mathrm{~nm}$ to $700 \mathrm{~nm}$ were given by Morel and Prieur (1977). Morel (1974) tabulated values from $350 \mathrm{~nm}$ to $600 \mathrm{~nm}$ for both pure water and typical seawater. The data were shown to fit a power law with a dependence on $\lambda^{-4.32}$, with seawater scattering around 1.30 times as much as pure water. This relationship has been used to extrapolate these data to the $660 \mathrm{~nm}, 870 \mathrm{~nm}$ and $1.6 \mu \mathrm{m}$ channels. The values obtained for $b_{\mathrm{w}}$ are $1.93 \times 10^{-3} \mathrm{~m}^{-1}$ at $550 \mathrm{~nm}, 8.77 \times 10^{-4} \mathrm{~m}^{-1}$ at $660 \mathrm{~nm}, 2.66 \times 10^{-4} \mathrm{~m}^{-1}$ at $870 \mathrm{~nm}$ and $1.91 \times 10^{-5} \mathrm{~m}^{-1}$ at $1.6 \mu \mathrm{m}$. The value predicted for $660 \mathrm{~nm}$ is in good agreement with that given for pure water at $660 \mathrm{~nm}$ in Morel and Prieur (1977) multiplied by 1.30 . The small size of $b_{w}$ (both in absolute terms and when compared to $\tilde{b}_{\mathrm{b}}$ ) at longer wavelengths means that any error in this extrapolation is minor in terms of influence on $\mathcal{R}_{\mathrm{w}}$.
The second parameter in Eq. (27), $\tilde{b}_{b}(\lambda)$, is the backscattering probability: the ratio of the backscattering to scattering coefficients of the pigments. It is related to the total concentration $C$ of chlorophyll $=a$ and pheophytin- $a$, measured in $\mathrm{mg} \mathrm{m}^{-3}$, and wavelength $\lambda$, measured in $\mathrm{nm}$, by the following expression:

$\tilde{b}_{\mathrm{b}}(\lambda)=0.002+0.02\left(0.5-0.25 \log _{10} C\right) \frac{550}{\lambda}$

The final term in the backscatter component of Eq. (27), $b$ is calculated as:

$b=0.3 C^{0.62}$

The relationship between $b$ and $C$ was derived by Morel (1988) for data at $550 \mathrm{~nm}$; the wavelength-dependence of particle backscattering is taken into account by the $\lambda^{-1}$ factor in Eq. (28). It should be noted that although parametrised in terms of $C$, the models were developed to account for scattering from suspended organic matter as well as pigment.

\subsubsection{Ratio multiplier $f$ and combination for water body reflectance $\mathcal{R}_{\mathrm{w}}$}

Morel and Prieur (1977) initially gave $f$, the empirical correction multiplier of the ratio of total backscattering to total absorption used to calculate the water body reflectance $\mathcal{R}_{\mathrm{w}}$, a value of 0.33 . Subsequent work has found it to depend on the solar geometry and the optical properties of water. The method used here was put forward by Morel and Gentili (1991), stated to be accurate within $1.5 \%$ for solar zenith angles smaller than $70^{\circ}$. It relates $f$ to the proportion of backscattering due to water molecules $\left(\eta_{\mathrm{b}}=b_{\mathrm{bw}} / b_{\mathrm{b}}\right)$ as follows:

$f=0.6279-0.2227 \eta_{\mathrm{b}}-0.0513 \eta_{\mathrm{b}}^{2}+\left(-0.3119+0.2465 \eta_{\mathrm{b}}\right) \cos \theta_{\mathrm{s}}$

Assuming a pigment concentration of $0.3 \mathrm{mg} \mathrm{m}^{-3}$, the variation of $f$ is small with wavelength but larger with solar angle, from slightly over 0.3 for a near-nadir sun to over 0.5 for a sun near the horizon.

\subsection{Magnitude of contribution}

Figure 9 shows $\rho_{\mathrm{ul}}$ at (A)ATSR wavelengths for a range of representative pigment concentrations. At the shorter wavelengths it is of the order of $10^{-2}-10^{-3}$, and so away from the glint region is generally equal to or larger than other contributions to $R_{\mathrm{bb}}$. Hence knowledge of $C$ is essential to judge accurately the total reflectance. As it shows a stronger wavelength-dependence than $\rho_{\mathrm{wc}}$ and $\rho_{\mathrm{gl}}$, the spectral shape of $R_{\mathrm{bb}}$ will be largely determined by $\rho_{\mathrm{ul}}$ outside of the sunglint region. At $870 \mathrm{~nm}$ and $1.6 \mu \mathrm{m}, \rho_{\mathrm{ul}}$ is negligible. At all wavelengths $\rho_{\mathrm{ul}}$ increases with $C$, although at $550 \mathrm{~nm} \rho_{\mathrm{ul}}$ decreases for $C>1 \mathrm{mg} \mathrm{m}^{-3}$ as the increased $a_{\mathrm{CDOM}(550)}$ used in the calculations causes absorption to increase more rapidly than scattering. 
Variation of underlight contribution with chlorophyll

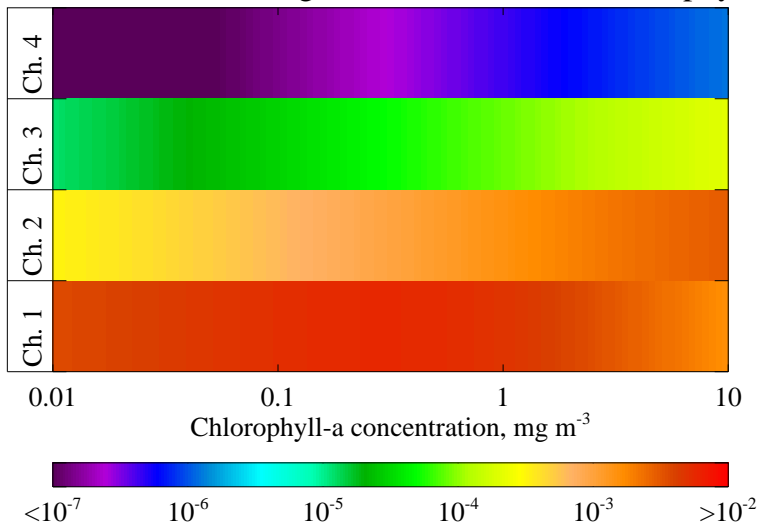

Fig. 9. Variation of $\rho_{\mathrm{ul}}$ with chlorophyll- $a$ concentration $C$ at the four (A)ATSR channels used. The solar zenith angle was taken as $30^{\circ}$, and $a_{\mathrm{CDOM}(550)}$ (in $\mathrm{m}^{-1}$ ) was set to $10 \%$ of $C$ (in $\mathrm{mg} \mathrm{m}^{-3}$ ) to represent the typically-covarying nature of these quantities in open waters as seen in Figs. 7 and 8.

\subsection{Uncertainties}

The major uncertainties associated with $\rho_{\mathrm{ul}}$ are errors arising from poor characterisation of pigment and CDOM distributions and scattering. The small size of the underlight term at the longer two wavelengths means that errors in $\rho_{\mathrm{ul}}$ will only have minor impacts on the modelled reflectance at $550 \mathrm{~nm}$ and $660 \mathrm{~nm}$.

- The relationship between $\tilde{b}_{\mathrm{b}}$ and $C$ was developed for Case I waters (according to the definitions of Morel and Prieur, 1977) and so may not accurately characterise scattering in Case II waters (where pigment and scattering particles do not covary in the same way). This may cause the algorithm to perform less well over Case II waters. Case II waters are largely coastal and the inhomogeneity of coastal regions presents other problems for aerosol retrieval; this is beyond the scope of this work.

- Errors arising from use of monthly means for chlorophyll and CDOM values. The GlobColour chlorophyll products have a stated accuracy of $31 \%$. CDOM errors are not given by Barrot et al. (2006). Further errors arise due to variations on shorter timescales than a month.

- There may be regional biases from using 0.014 as a global CDOM spectral slope $S$, as Roesler et al. (1989) found values from 0.011 to 0.018 in different parts of the world.

\section{Typical values, patterns, and errors}

To illustrate typical reflectances predicted by the model, it has been applied to a selection of AATSR orbits from 6 September 2004. Information on the viewing solar-satellite geometry is shown in Fig. 10, along with the ECMWF nearsurface wind speed from noon on that date.

Figures 11 and 12 show example nadir-view and forwardview BRDFs generated at $550 \mathrm{~nm}$ and $1600 \mathrm{~nm}$. Sun-glint is visible in the centre of the nadir-view swaths and toward the north of the forward-view swaths. These glint patterns persist for different orbits as the satellite geometry remains the same. Perturbations to this glint shape arise due to variations in the wind speed and from increased reflectance due to oceanic whitecaps or underlight, particularly at $550 \mathrm{~nm}$. BRDF at $660 \mathrm{~nm}$ and $870 \mathrm{~nm}$ takes values in between these two wavelengths; at $550 \mathrm{~nm}$ all contributions to the BRDF are important, while at $1600 \mathrm{~nm}$ the shape is glint-dominated, unless wind speeds are high. The exact location of the glint region varies seasonally.

The sea surface BRDF for (A)ATSR is observed to take values from around $10^{-5}$ to 1 dependent on the wavelength and location with respect to the sun-glint region. The highest values are observed for shortest wavelengths; near the glint region the BRDF can be nearly spectrally flat while far away there can be orders of magnitude difference.

The DHR, shown at $550 \mathrm{~nm}$ and $1600 \mathrm{~nm}$ in Fig. 13 for the same swaths as the previous BRDF example, is almost identical for both of AATSR's viewing geometries (whose solar angles differ by under $1^{\circ}$ for any given pixel). Values increase as the solar zenith angle increases; as with the shape of the BRDF, perturbations to the basic shape arise due to the wind and pigment distribution. The same scale is used as in FigS. 11 and 12 to illustrate the comparative variability of the reflectances. Again, values at $660 \mathrm{~nm}$ and $870 \mathrm{~nm}$ are intermediate between these two wavelengths. The DHR typically takes value around $10^{-2}$ (where the Sun is high) to $10^{-1}$ (where the Sun is low), and is slightly larger at shorter wavelengths.

Figure 14 shows the a priori BHR generated for these overpasses. Being independent of geometry it is the same for both instrument viewings and variability over the globe is determined by wind and pigment distributions: the glint shape of the BRDF is "averaged out" by the integration, which contributes around 0.05 to the albedo. The BHR is spectrally flatter and less variable than the BRDF or DHR. Typical values are in the range 0.05-0.08 at all wavelengths, with the shortest wavelengths being brightest. The same scale is again used as in Figs. 11 and 12, to illustrate this comparative lack of variability. 

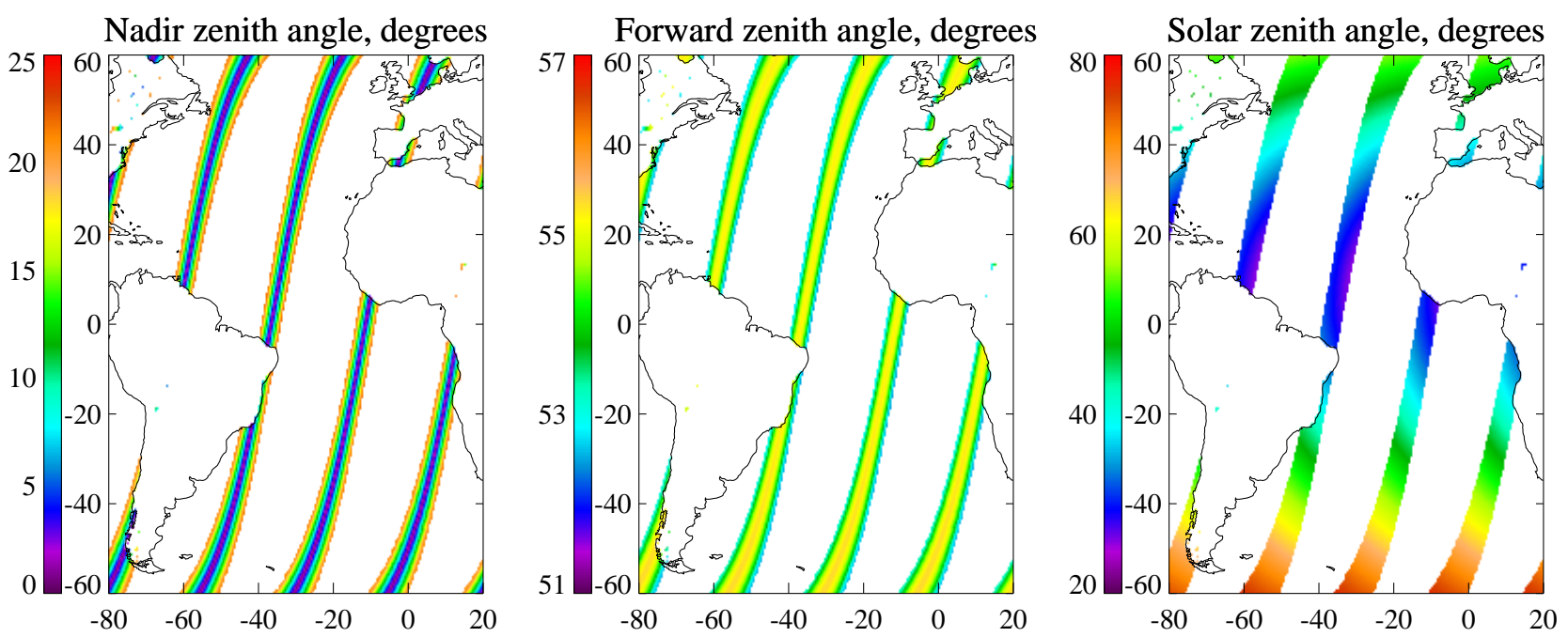

Nadir relative azimuth, degrees

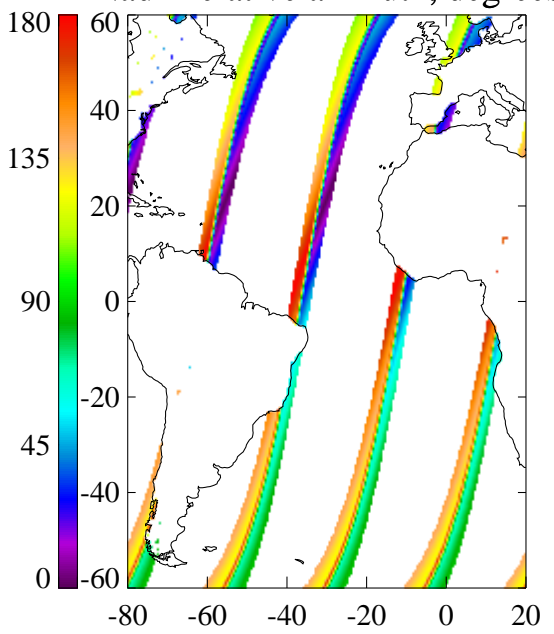

Forward relative azimuth, degrees
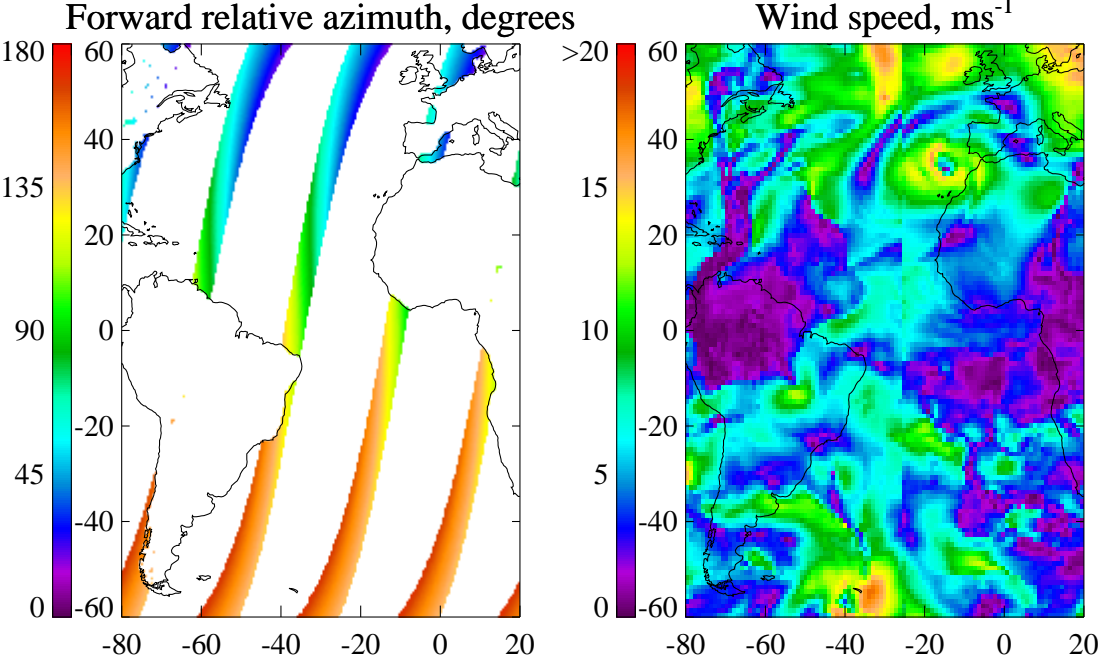

Fig. 10. Viewing geometry and wind speed for AATSR swaths on 6 September 2004. The top row shows (left-right) the nadir view satellite zenith angle, forward view satellite zenith angle, and solar zenith angle. The bottom row shows (left-right) the nadir-view relative azimuth angle, the forward-view relative azimuth angle, and the 12:00 p.m UTC ECMWF $10 \mathrm{~m}$ wind speed.

\subsection{A priori uncertainty}

It is important to assign a reasonable error to the a priori albedo generated: too small a variability and the retrieval will be unduly constrained by an imperfect model, but too large a variability and some of the information on the state is effectively thrown away. Appropriate uncertainties have been determined in the following way:

- Generation of 10000 random sets of typical ocean and viewing states (for example differing wind speeds, chlorophyll concentrations and geometries).

- For each ocean state, generation of $R_{\mathrm{bb}}$ and integration for $R_{\mathrm{bd}}$ and $R_{\mathrm{dd}}$ for an ensemble (50 members each) of random perturbations to the uncertain model parameters (such as the foam reflectance, or sea slope characteristics from Cox and Munk, 1954a). The magnitude of the perturbations is determined by the stated uncertainty on the model parameter as previously described in the text.

- Calculation of the ensemble median reflectance and its standard deviation for each ocean state, for each of $R_{\mathrm{bb}}$, $R_{\mathrm{bd}}$ and $R_{\mathrm{dd}}$. Use of medians decreases the sensitivity to outliers.

Figure 15 shows the calculated median and standard deviation of $R_{\mathrm{dd}}$ for the ensembles considered. The standard deviation is observed to vary with the magnitude of $R_{\mathrm{dd}}$. The ratio of the ensemble standard deviation to the median is a measure of the proportional sensitivity of the state to errors in 

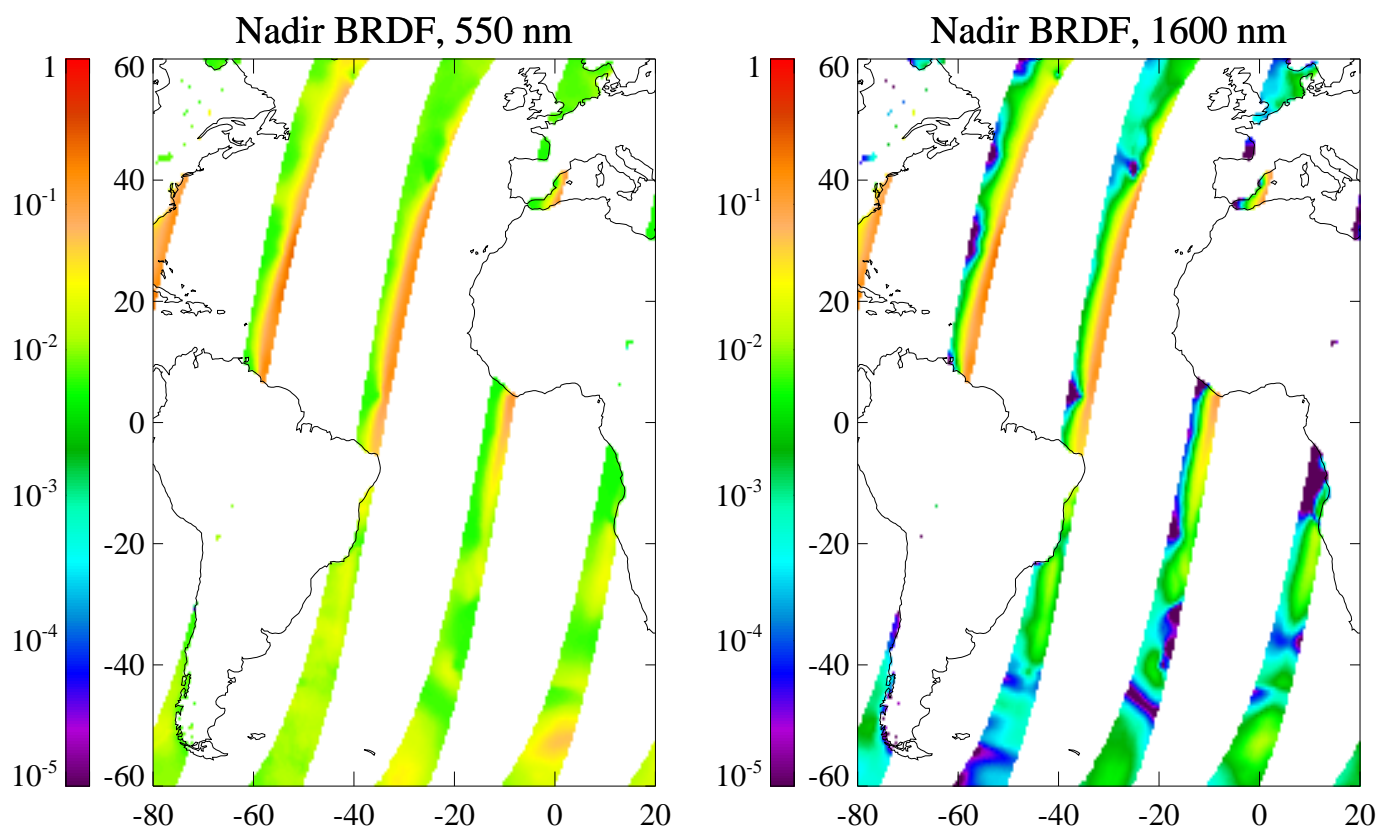

Fig. 11. Nadir-view sea BRDF at $550 \mathrm{~nm}$ (left) and $1600 \mathrm{~nm}$ (right). Data for AATSR swaths on 6 September 2004.
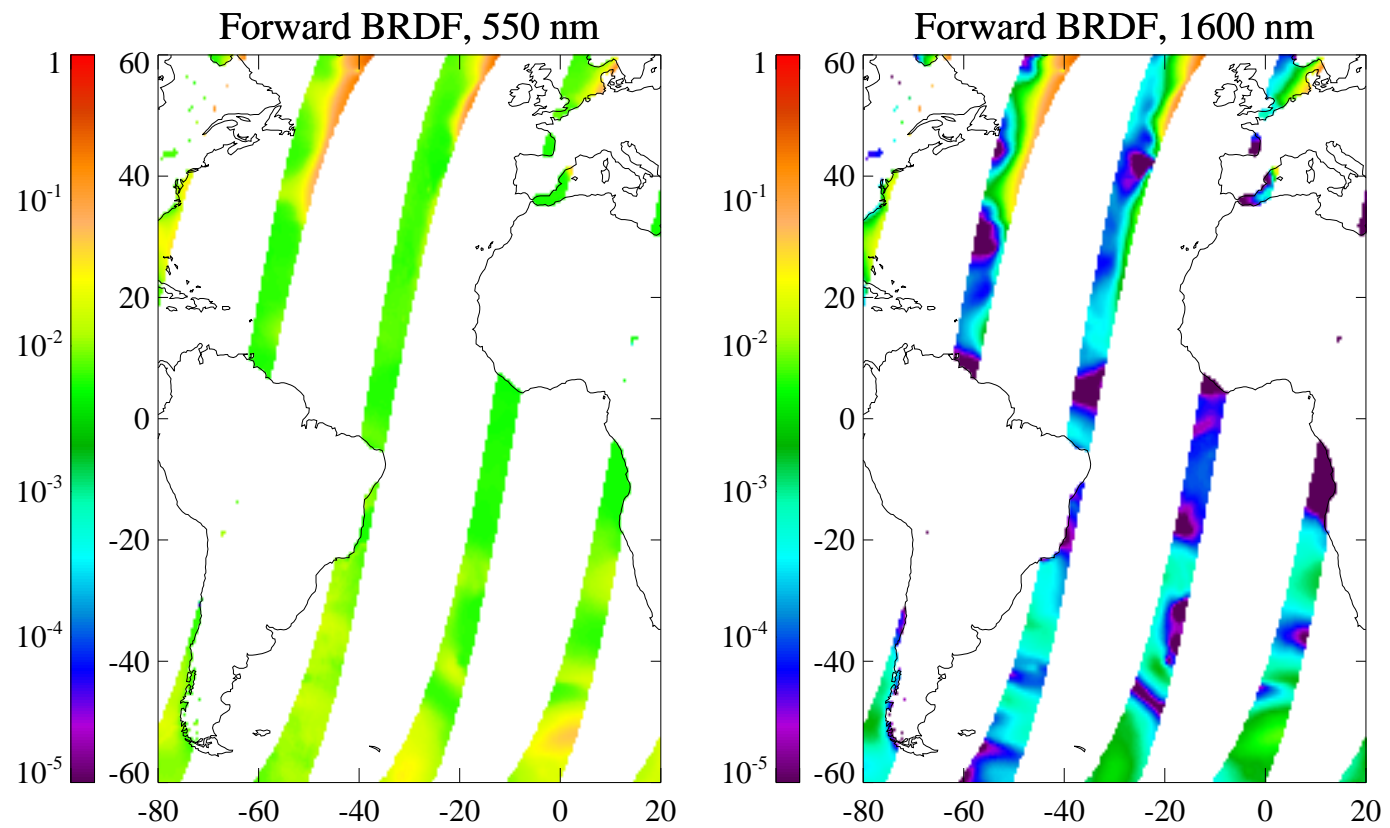

Fig. 12. Forward-view sea BRDF at $550 \mathrm{~nm}$ (left) and $1600 \mathrm{~nm}$ (right). Data for AATSR swaths on 6 September 2004.

the model parameters: a larger ratio means that the calculated reflectance or albedo is more sensitive to errors in the model parameters.

Over all states, the median of these sensitivity ratios for $R_{\mathrm{dd}}$ is 0.20 to 2 decimal places at all wavelengths. The similarity between wavelengths is an indicator that the dominating terms (the integrated glint contribution), are similar for each. In the retrieval, multiplying these sensitivities by the a priori BHR gives the a priori error estimate for the BHR for each ground scene.

As the ratios $R_{\mathrm{dd}}: R_{\mathrm{bb}}$ and $R_{\mathrm{dd}}: R_{\mathrm{bd}}$ are fixed in the retrieval forward model, analagous values for the sensitivity of $R_{\mathrm{bd}}$ and $R_{\mathrm{bb}}$ to uncertainties in model inputs are useful to determine the sensitivity of the forward model to the fixed 

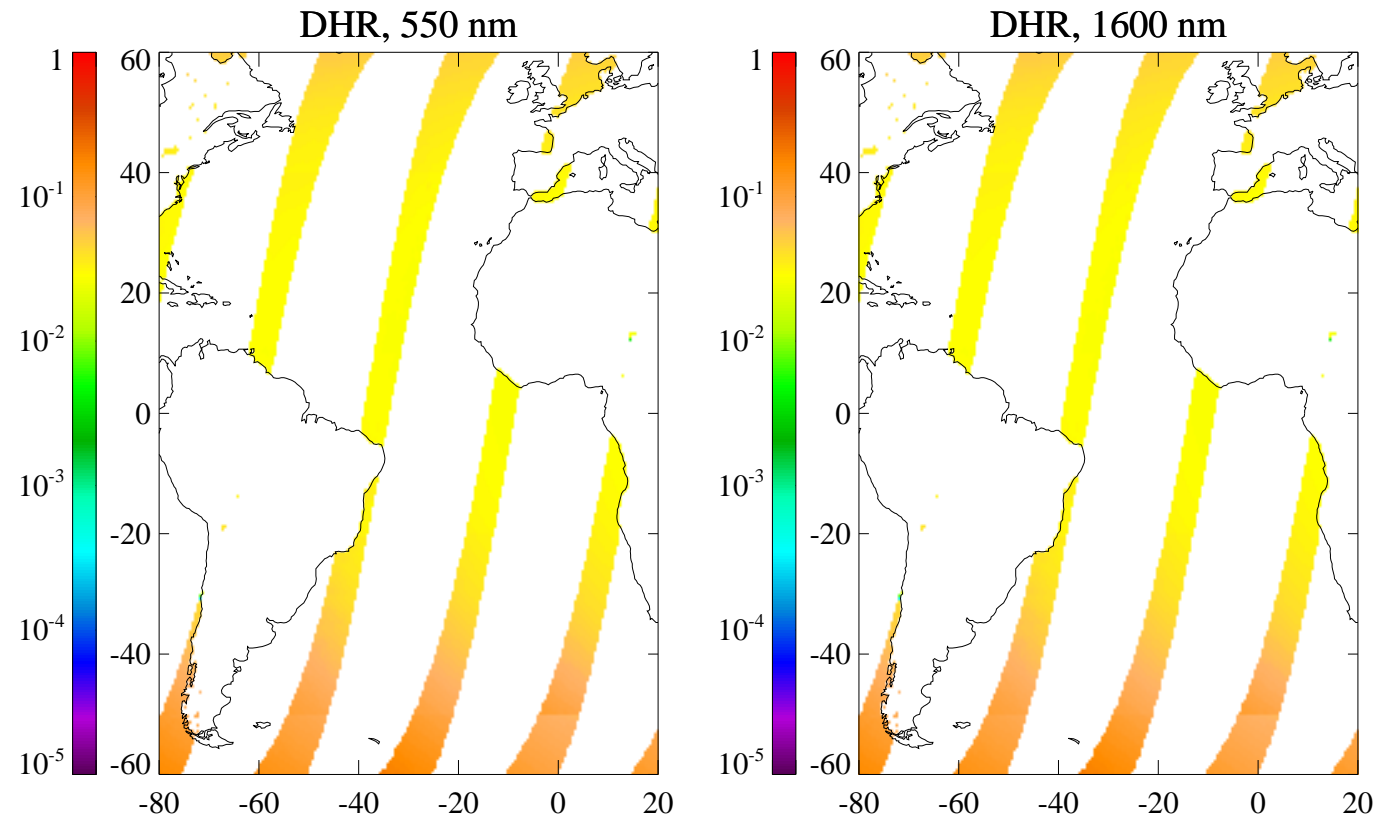

Fig. 13. Sea DHR at $550 \mathrm{~nm}$ (left) and $1600 \mathrm{~nm}$ (right). Data for AATSR swaths on 6 September 2004.
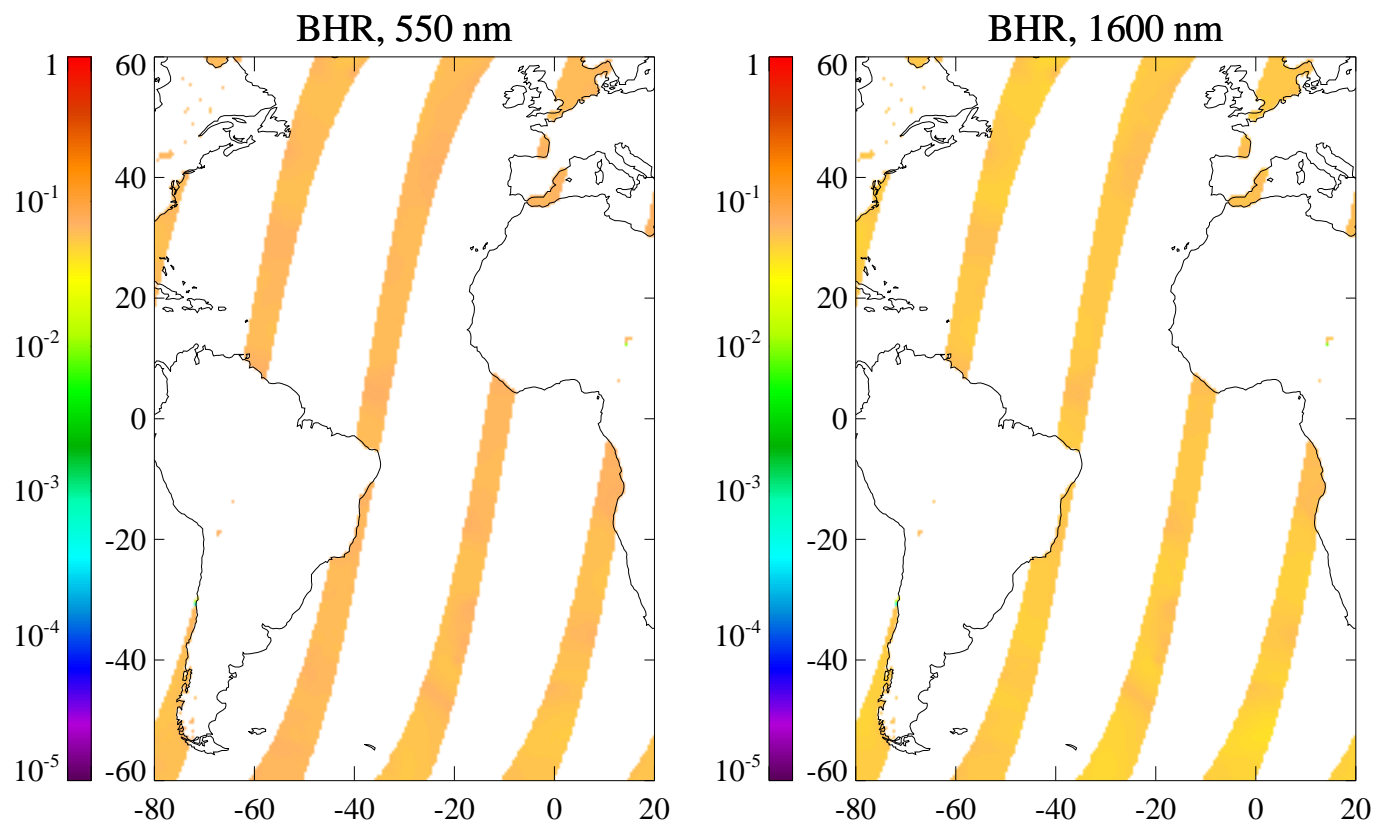

Fig. 14. Sea BHR at $550 \mathrm{~nm}$ (left) and $1600 \mathrm{~nm}$ (right). Data for AATSRs swath on 6 September 2004.

ratios. For the DHR, these median relative uncertainties are 0.22 at $550 \mathrm{~nm}$ and 0.20 at longer wavelengths. As the BRDF spans several orders of magnitude, dependent on wavelength and position relative to the sun-glint, calculation of a relative uncertainty is not always useful (as the relative uncertainty on a dull BRDF may be high, even when the abso- lute uncertainty on it is not). As a result some minimum threshold for the uncertainty is imposed based on the median absolute uncertainty determined for dull BRDFs. The median relative uncertainty on $R_{\mathrm{bb}}$ for the nadir view is 0.81 at $550 \mathrm{~nm}, 0.75$ at $660 \mathrm{~nm}, 0.69$ at $870 \mathrm{~nm}$ and 0.63 at $1.6 \mu \mathrm{m}$ with minimum absolute uncertainties of $0.01,0.008,0.006$ 

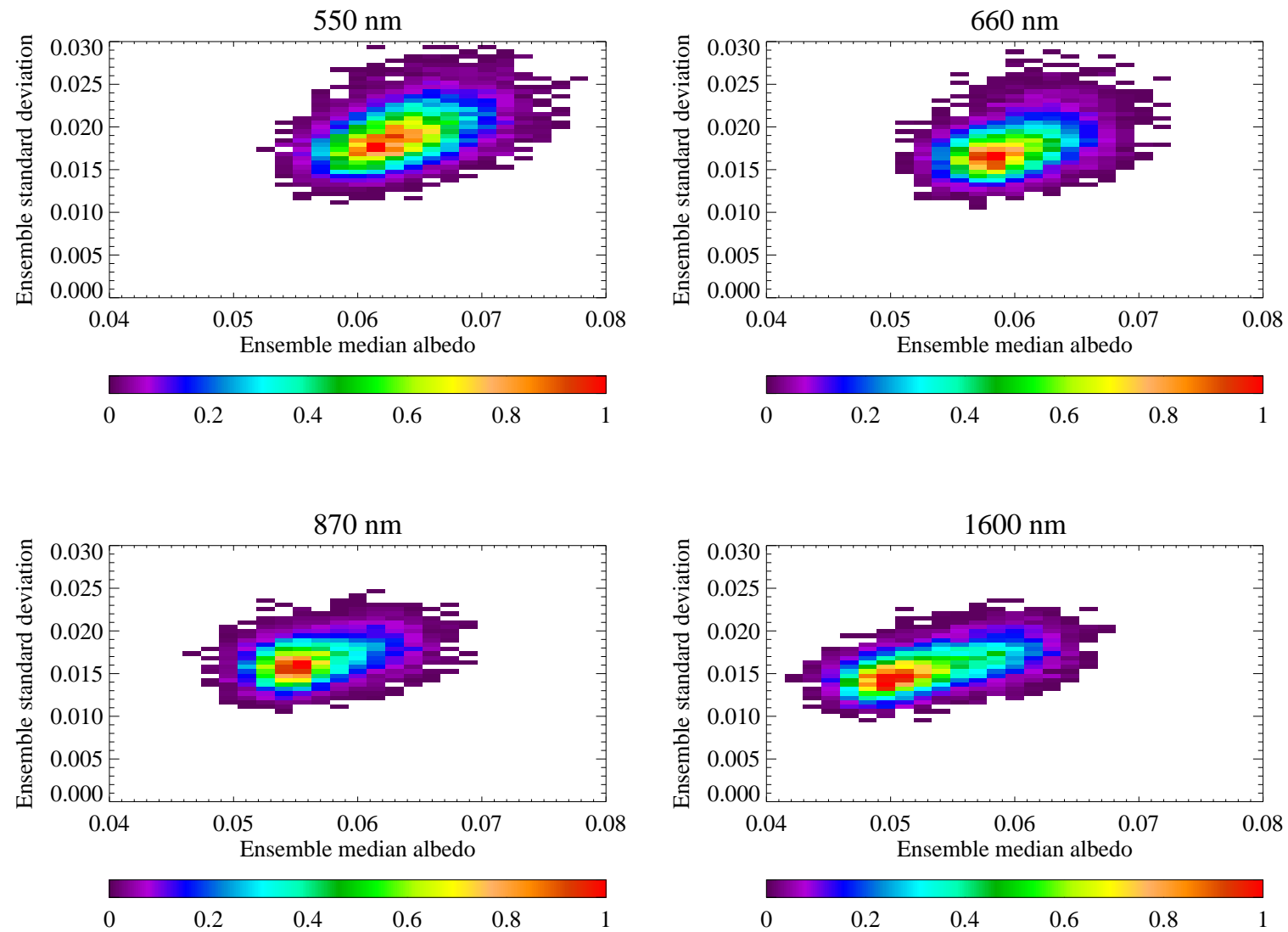

Fig. 15. Joint histograms of ensemble median $R_{\mathrm{dd}}$ against the standard deviation of the ensemble's $R_{\mathrm{dd}}$, for (A)ATSR visible/nIR wavelengths. The colour scale indicates the relative density of points.

Table 5. Forward model uncertainty in TOA reflectance, in units of the percentage of the measured signal, arising from uncertainty in the ratios $R_{\mathrm{dd}}: R_{\mathrm{bb}}$ and $R_{\mathrm{dd}}: R_{\mathrm{bd}}$.

\begin{tabular}{ccc}
\hline Wavelength & Nadir view & Forward view \\
\hline $550 \mathrm{~nm}$ & 2.00 & 1.32 \\
$660 \mathrm{~nm}$ & 2.36 & 1.50 \\
$870 \mathrm{~nm}$ & 2.63 & 1.61 \\
$1600 \mathrm{~nm}$ & 4.61 & 2.94 \\
\hline
\end{tabular}

and 0.005 , respectively. For the forward view, relative uncertainties are $0.82,0.73,0.64$ and 0.58 with minimum values of $0.007,0.004,0.002$ and 0.001 for the four channels. The higher uncertainties at shorter wavelengths arise due to the fact that whitecaps, glint and underlight may all contribute significantly to $R_{\mathrm{bb}}$ at these wavelengths.
For more details on the calculation of the contribution of uncertainties in the fixed ratios $R_{\mathrm{dd}}: R_{\mathrm{bb}}$ and $R_{\mathrm{dd}}: R_{\mathrm{bd}}$ to the forward model error budget the reader is referred to Sayer (2008). The calculated contribution in terms of percentage uncertainty on the TOA reflectance is given in Table 5. These values are of a similar order of magnitude to the measurement uncertainty (Smith et al., 2001, 2008), and increase with wavelength as the atmospheric contribution to TOA reflectance decreases. Forward-view values are lower due to the longer atmospheric path length. The corollary of this is that, when one view is observing the glint region (bright TOA reflectance), its measurements receive less weight in the retrieval.

\section{Application to aerosol retrievals}

The new sea surface reflectance algorithm has been used to peform aerosol retrievals from AATSR data in the southeast Pacific $\left(60^{\circ} \mathrm{S}-0^{\circ} \mathrm{S} ; 180^{\circ} \mathrm{W}-60^{\circ} \mathrm{W}\right)$ for the month of September 2004. This region is chosen because it contains a large region of open ocean, far from strong aerosol source regions. The background mid-visible AOD in these open 
oceanic regions is typically $<0.1$ (Smirnov et al., 2009), meaning an accurate model of the surface reflectance is of importance to determine the surface and atmospheric contributions to the TOA reflectance. Additionally, this area contains coastal regions of high chlorophyll concentration and open regions of low chlorophyll concentration (Fig. 7), and while wind speeds over the bulk of the area are from 5$8 \mathrm{~ms}^{-1}$, the region from approximately $45^{\circ} \mathrm{S}-60^{\circ} \mathrm{S}$ typically has stronger winds in the region of $10 \mathrm{~ms}^{-1}$ or higher (see Fig. 3). For these retrievals, the most recent version of the AATSR visible channel calibration trend data are used (v12). Results are only presented for sea retrievals.

The OE method (Rodgers, 2000) allows an analysis of retrieval performance through examination of retrieval statistics. Additionally, comparisons of aerosol optical depth with satellite data from the MODIS-Terra instrument (Remer et al., 2005), and with ground-based observations from MAN cruises in the region (Smirnov et al., 2009), and the AERONET site on the island of Tahiti (Holben et al., 1998), are possible.

\subsection{Aerosol retrieval statistics}

The principle of $\mathrm{OE}$ is to maximise the conditional probability of the retrieved state given measurements and any a priori information. Formally, this is the maximum of $P=P\left(\boldsymbol{x} \mid \boldsymbol{y}, \boldsymbol{x}_{a}, \boldsymbol{b}\right)$ with respect to the values of the state vector $\boldsymbol{x}$ for a measurement vector of reflectances $\boldsymbol{y}$, where $\boldsymbol{x}_{a}$ is the a priori value of the state vector and $\boldsymbol{b}$ are all other parameters not modelled by the forward model. The assumption is made that errors in the measurements, a priori and model parameters have Gaussian distributions with zero mean and covariance matrices given by $\mathbf{S}_{y}, \mathbf{S}_{x}$ and $\mathbf{S}_{b}$, respectively. Following Rodgers (2000) the maximum probability is given for the minimum of $J$, the retrieval cost:

$J(x)=\left(\boldsymbol{y}(\boldsymbol{x})-\boldsymbol{y}_{m}\right) \mathbf{S}_{y}^{-1}\left(\boldsymbol{y}(\boldsymbol{x})-\boldsymbol{y}_{m}\right)^{T}+\left(\boldsymbol{x}-\boldsymbol{x}_{a}\right) \mathbf{S}_{x}^{-1}\left(\boldsymbol{x}-\boldsymbol{x}_{a}\right)^{T}$

The terms present in the equation represent weighted deviations from measurements and the a priori state. Here $\boldsymbol{y}(\boldsymbol{x})$ refers to the values of $\boldsymbol{y}$ predicted by the forward model from the current value of the state vector; for clarity, the measurement vector is denoted by $\boldsymbol{y}_{m}$. The minimisation is done with respect to $\boldsymbol{x}$, so that the derivative of $J$ is independent of $\boldsymbol{b}$. The impact of $\mathbf{S}_{b}$, the model parameter error, on $J$ is included by mapping it into measurement space and including it as a contribution to $\mathbf{S}_{y}$. In this case examples of these model parameters include the fixed ratios $R_{\mathrm{dd}}: R_{\mathrm{bb}}$ and $R_{\mathrm{dd}}: R_{\mathrm{bd}}$, set by the surface reflectance model.

Operationally, $J$ is normalised by the number of measurements (here, 8) before being output by ORAC. Standard quality controls are applied to retrievals to exclude those poorly fit (typically a result of cloud contamination). This involves considering only those scenes retrieved with a normalised cost lower than 10. Additionally, only the maritime aerosol model was used. The distribution of residual costs is shown in Fig. 16, for both the total cost and the components corresponding to deviations from measurements and a priori. Retrieved AOD and effective radius have a large a priori uncertainty, so $J$ is dominated by contributions from the fits of the measurements, and retrieved minus a priori BHR.

With 8 measurements and 4 constrained state vector elements, it is expected that a well-fit retrieval will have normalised cost on the order of $1.5(=12 / 8)$, with approximately 1 coming from measurements and 0.5 from a priori. The overall distributions should correspond to $\chi^{2}$ distributions with these numbers of degrees of freedom. There should be few cases of costs exceeding triple these values (approximately 4.5 for the total cost). Figure 16 shows that the distribution of actual residuals broadly matches these theoretical considerations, suggesting the uncertainties in the retrieval are well-characterised. The total cost is a good match for a $\chi^{2}$ distribution for 1.5 degrees of freedom. The figure is truncated at $J=5$; the number of retrievals with $J>5$ is negligible. Slightly higher proportions of retrievals with $0.5<J<1$ than expected are likely due to the fact that there are constraints, albeit weak, from the a priori AOD and effective radius so the true number of degrees of freedom is actually slightly higher than 1.5 . Due to the low number of retrievals with $4.5<J<10$, the results presented here do not change significantly if a stricter cost threshold is adopted.

As discussed, when the residuals $\left(\boldsymbol{y}(\boldsymbol{x})-\boldsymbol{y}_{m}\right.$ or $\left.\boldsymbol{x}-\boldsymbol{x}_{a}\right)$ are weighted by their uncertainties (square roots of appropriate elements of $\mathbf{S}_{y}$ or $\mathbf{S}_{x}$ ) these distributions should each approximate Gaussians with mean 0 and variance 1 . As well as the total cost, the distributions of error-normalised residuals may be examined individually to see whether each measurement or parameter is particularly well or poorly fit. Figure 17 shows the normalised residuals on the measurements, and Fig. 18 on a priori BHR. It would be expected that approximately $68 \%$ of the data should fall within the range \pm 1 and $99 \%$ within \pm 3 . These figures show that, on the whole, the distributions meet these expectations, which shows again a good representation of uncertainties in the retrieval algorithm. Some distributions show a degree of bimodality, which may indicate differing deficiencies in the aerosol or surface models in some situations, although biases are small. The residual distributions on white-sky albedo are slightly narrower than expected, indicating that the BHR predicted by the reflectance model is slightly more precise than the error analysis estimated. The $550 \mathrm{~nm}$ residual distribution has a small positive bias, suggesting that surface reflectance at this wavelength is slightly brighter than the model predicts.

The exception is the $1.6 \mu \mathrm{m}$ reflectance residual, which tends to be negative and wider than expected for the nadir view. As AOD is generally much lower in the nIR than visible region, the bulk of the information on optical depth is obtained from the shorter-wavelength channels, and so the poorer nadir-view $1.6 \mu \mathrm{m}$ fit should not lead to significant errors in AOD. The width suggests that, in some situations, 


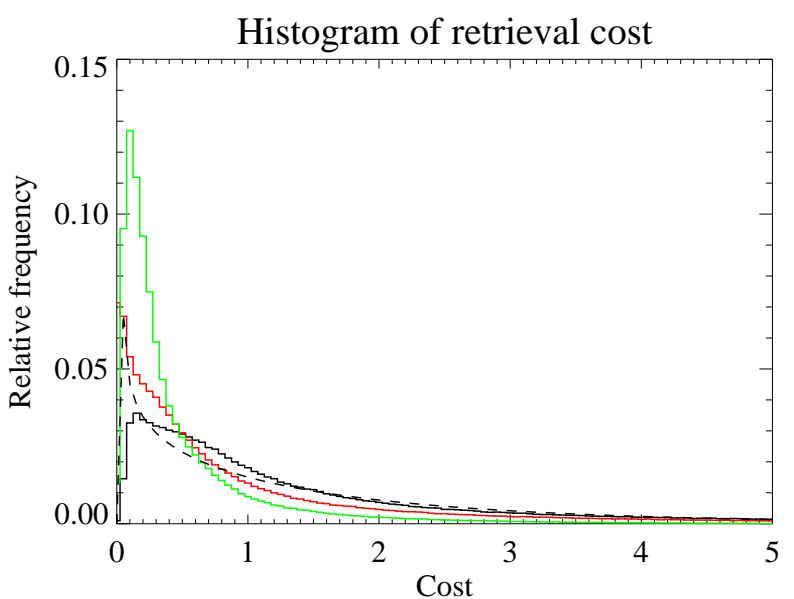

Fig. 16. Relative frequency distribution of retrieval cost, $J$. Total cost is shown in black, while distributions for measurement and a priori contributions are shown separately in red and green, respectively. The scale indicates the proportion of all observations falling in that bin. The dashed black line indicates the theoretical $\chi^{2}$ disribution for total cost.

the forward model error for this view and channel should be larger to represent accurately the precision with which this measurement can be fit. More generally, the measurement residual distributions have a larger negative tail for the nadir view and positive for the forward view. The reasons for this are uncertain and may be due to either a poorer representation of aerosol or surface properties at nadir-viewing geometries, or alternatively issues with the data put into the surface reflectance model. An additional possibility is calibration issues over dark targets; existing vicarious calibration of the ATSR instruments has focussed on bright targets (Smith et al., 2002, 2008). A small calibration offset may be hidden in the signal from a bright target, but count more for an otherwise dark signal.

\subsection{Intercomparison of aerosol optical depth}

Retrieved AOD from ORAC-AATSR is compared with that obtained from the MODIS sensor aboard the satellite Terra. ENVISAT's daytime overpass is approximately 10:00 a.m. local solar time; the Terra platform shares a similar overpass time of 10:30 a.m., as opposed to Aqua's 01:30 p.m. From this point, MODIS will be taken to refer to MODIS-Terra. The QA-weighted mean ocean AOD and standard deviation, from the Collection 5 level 3 daily MODIS atmosphere product (MOD08_D3), are used. This is provided on a $1^{\circ}$ grid; before the comparison, the AATSR retrievals are aggregated onto the same grid. AATSR retrievals are weighted by the relative uncertainty on retrieved AOD, as provided by OE. At least 6 retrievals must be present in each bin. To migitate the effects of sampling (MODIS's swath is over $2000 \mathrm{~km}$ as compared to the approximately $550 \mathrm{~km}$ AATSR swath, and they are not on the same orbital track), the gridded data are compared only when both MODIS and AATSR provide aerosol retrievals on a given day.

Monthly mean fields of $550 \mathrm{~nm}$ AOD have been calculated from the daily mean fields for both instruments, and are shown in Fig. 19. Coverage is incomplete and largely limited by AATSR's narrower swath, MODIS elimination of high-sediment and sun-glint regions and overall high cloudiness. This low sampling means that features in individual orbits may still be seen in the monthly means. There is a good spatial correlation between the two, although AATSR retrieves lower AOD (typically 0.02-0.1) than MODIS (typically $0.07-0.2$ ). Elevated AOD in open ocean regions in both correspond to higher aerosol loadings from windier conditions; although various relationships between wind speed and marine AOD have been proposed (for example, recently Smirnov et al., 2003, Glantz et al., 2009; Huang et al., 2009; Lehahn et al., 2010), all suggest higher winds lead to higher AOD.

Aerosol data from cruises in the Maritime Aerosol Network are available for the study region. The low spatial and temporal coverage of these limits the ability to directly compare with satellite data, although they may be used to provide some information about typical AOD for different regions and its variability. The cruises used are as follows:

- NOAA Ronald H. Brown Cruise, December 2007Feburary 2008. Latitudinal transect through the eastern Pacific.

- NOAA Ronald H. Brown Cruise, October-November 2008. Measurements from the vicinity of Arica, Bolivia out to the west, then north towards the Ecuadoran coast.

- RV Meteor Cruise, October 2008-February 2009. Across the Pacific coast of South America.

- RV Hesperides Cruise, February-March 2009. Across the Pacific coast of the southern part of South America.

- RV Melville Cruise, November 2009-February 2010. Transect from Brisbane, Australia to Valparaiso, Chile.

Measurements during these cruises were made using Microtops sun photometers (Smirnov et al., 2009); although $\mathrm{AOD}$ at $550 \mathrm{~nm}$ is not retrieved from these measurements, it is estimated from the AODs recorded at $440 \mathrm{~nm}$ and $870 \mathrm{~nm}$ and the Ångström exponent between these two wavelengths. Level 2.0 data (cloud-cleared and quality-assured) were used for all cruises except RV Melville 2009-2010, where level 2.0 was not yet available so level 1.5 (cloud-cleared and corrected for pointing errors) were used. The daily average AOD at $550 \mathrm{~nm}$ reported from these cruises is shown in Fig. 20. The standard deviation about these daily values was generally small $(<0.01)$. Highest optical depths, on occasion exceeding 0.4, were found in coastal regions. Typical AOD for the open ocean is in the region $0.05-0.09$, interim between 

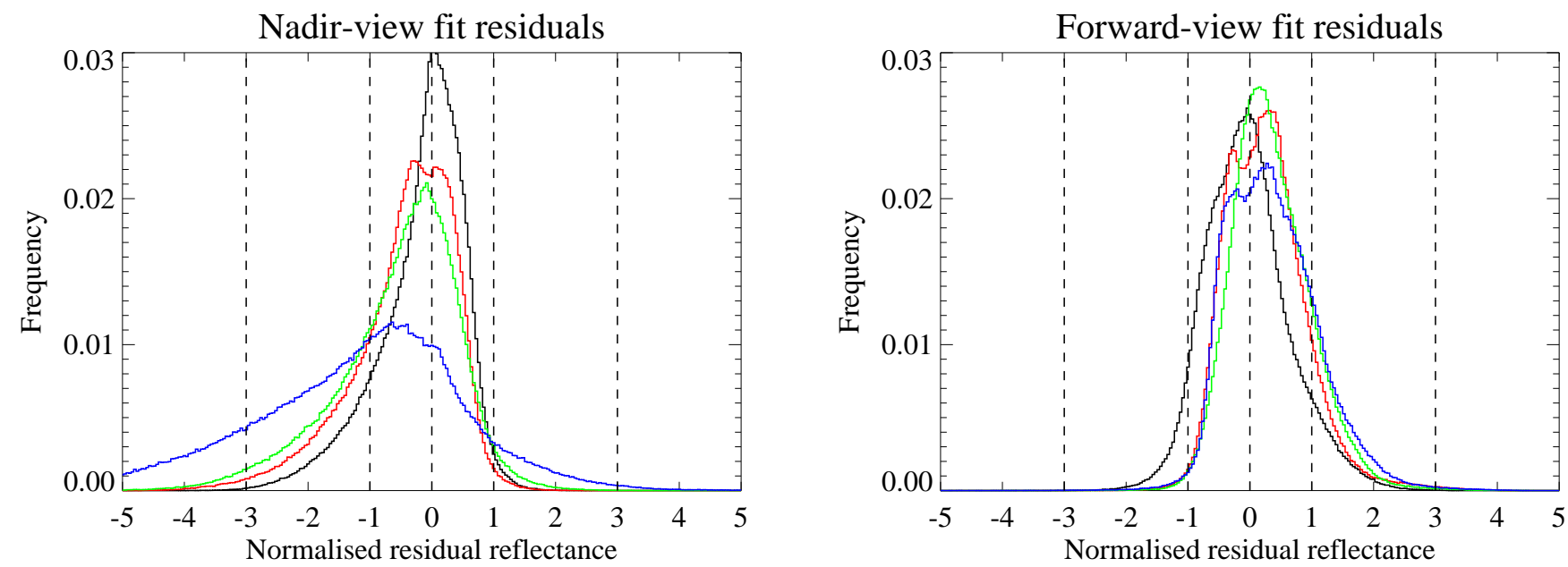

Fig. 17. Error-normalised residuals on nadir (left) and forward-view (right) measurements for aerosol retrievals in the southern Pacific during September 2004. In both plots, black indicates $550 \mathrm{~nm}$, red $660 \mathrm{~nm}$, green $870 \mathrm{~nm}$ and blue $1.6 \mu \mathrm{m}$. The vertical lines indicate 0 , \pm 1 and \pm 3 , respectively. The scale indicates the proportion of all observations falling in that bin.

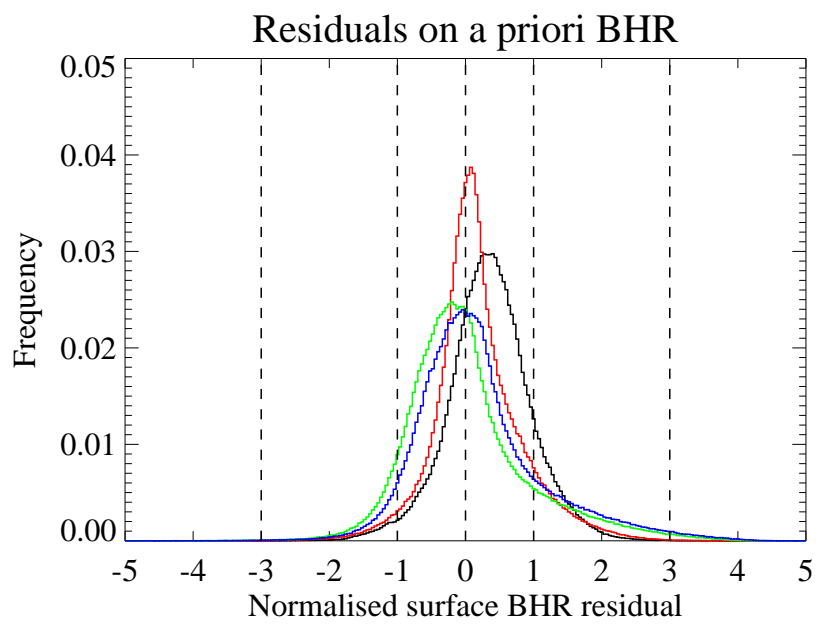

Fig. 18. Error-normalised residuals on a priori BHR for aerosol retrievals in the southern Pacific during September 2004. Black indicates $550 \mathrm{~nm}$, red $660 \mathrm{~nm}$, green $870 \mathrm{~nm}$ and blue $1.6 \mu \mathrm{m}$. The vertical lines indicate $0, \pm 1$ and \pm 3 , respectively. The scale indicates the proportion of all observations falling in that bin.

MODIS and AATSR. Where both are available, in most cases the difference in daily mean AOD between the level 1.5 and level 2.0 data is negligible. For the few cases in which the level 1.5 and 2.0 data are significantly different, level 1.5 data generally have $\mathrm{AOD}>0.2$, and the corresponding level 2.0 AODs are lower by 0.01-0.04.

The AERONET site at Tahiti $\left(17.577^{\circ} \mathrm{S}, 149.06^{\circ} \mathrm{W}, 90 \mathrm{~m}\right.$ elevation) did provide aerosol measurements during September 2004; these are available at level 1.5, and here $550 \mathrm{~nm}$ AOD is estimated from that retrieved at $500 \mathrm{~nm}, 870 \mathrm{~nm}$ and the Ångström exponent between these wavelengths. A time series of daily mean $550 \mathrm{~nm}$ AOD is shown in Fig. 21, with the standard deviation about the daily average given as an uncertainty estimate. Also shown are the MODIS and AATSR mean and standard deviation AOD for the $1^{\circ}$ grid box in which Tahiti falls. The $550 \mathrm{~nm}$ AOD measured at the AERONET site is typically between 0.03-0.07. Although the number of cloud-free satellite overpasses of the region is low, the figure suggests a tendency for MODIS to overestimate the AOD as compared to AERONET (although the variability of the MODIS data are high), and AATSR to underestimate. Disagreement would also arise if the Tahiti AERONET site were not representative of the larger area, although in this case the impact would be the same for both satellite datasets.

Histograms of the monthly mean satellite AOD, as well as the ground-based measurements, are presented in Fig. 22. As the majority of the satellite observations are open ocean (Fig. 19), the MAN cruises are restricted to those two which went through this region, Ronald H. Brown (2007-2008) and RV Melville (2009-2010). Additionally, the AOD observed at the AERONET Tahiti site is shown. All ground-based measurements, as opposed to daily averages, were used to generate the histograms. Together, these give some indication of typical AODs found in the region, although neither satellite dataset would be expected to match as these may not represent the whole region well. Also shown is a histogram corresponding to the AATSR data reprocessed assuming a fixed wind speed of $6 \mathrm{~ms}^{-1}$, and the overall surface reflectance fixed at the value predicted by the model, as in the MODIS Collection 5 algorithm (Remer et al., 2005).

The ORAC-AATSR AOD histogram is both narrower and takes smaller values than the MODIS histogram. When the wind speed is fixed at $6 \mathrm{~ms}^{-1}$ and the AATSR data repro- 

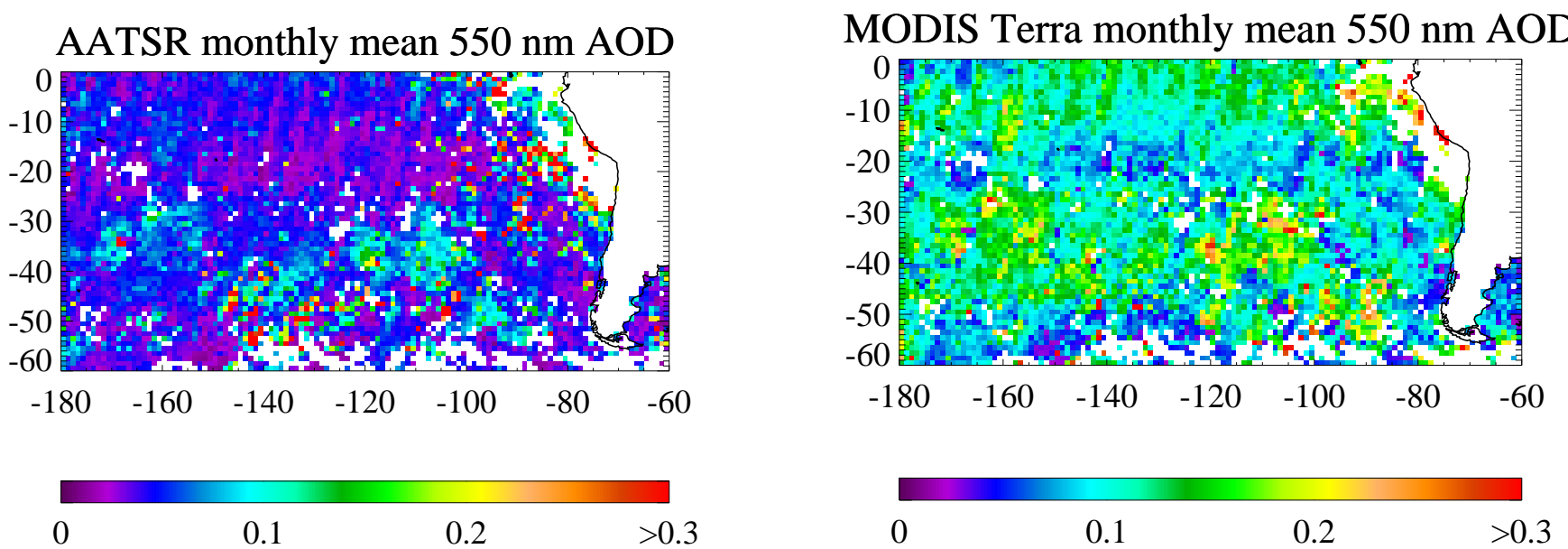

Fig. 19. Monthly mean $550 \mathrm{~nm}$ AOD from AATSR (left) and MODIS-Terra (right) on a $1^{\circ}$ grid, constructed from only those grid cells where AATSR and MODIS-Terra reported observations on the same day.

MAN daily mean $550 \mathrm{~nm}$ AOD

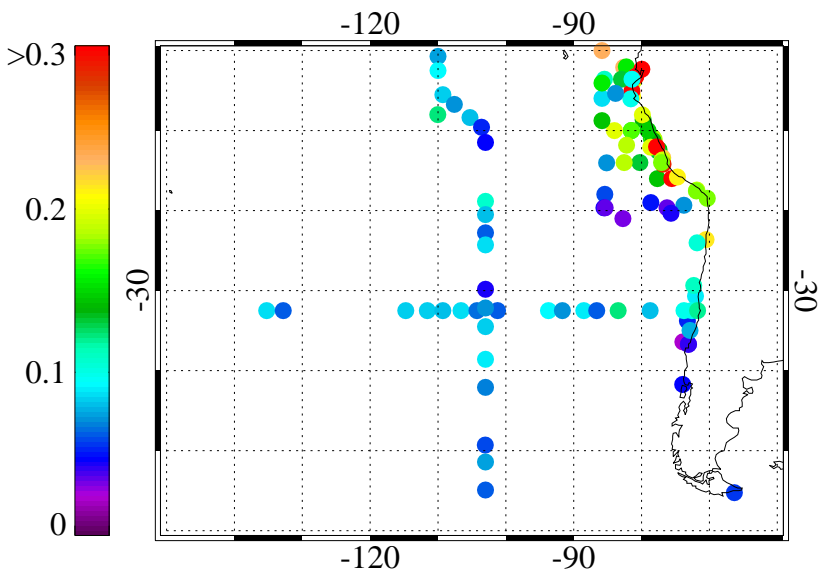

Fig. 20. Daily mean $550 \mathrm{~nm}$ AOD from MAN measurements in the southern Pacific.

cessed, the overall distribution of AOD is observed to slightly broaden and the peak shifted to higher AOD by around 0.01 . This indicates that some of the broadness and positive offset of MODIS as compared to AATSR may be explained by the assumption about a fixed surface reflectance and wind speed. In this respect, the assumptions about wind speed made in the MODIS aerosol retrieval are likely to lead to an overestimate of AOD in windy $\left(w>6 \mathrm{~ms}^{-1}\right)$ conditions. A higher MODIS AOD could also arise if MODIS underestimated the underlight reflectance, although this is small over large parts of the region considered due to low chlorophyll $a$ concentrations, and so unlikely to be important. Kaufman et al. (2005) examined the effect of residual cloud contamination on MODIS AODs over ocean and concluded that at $550 \mathrm{~nm}$ contamination, principally from thin cirrus, could

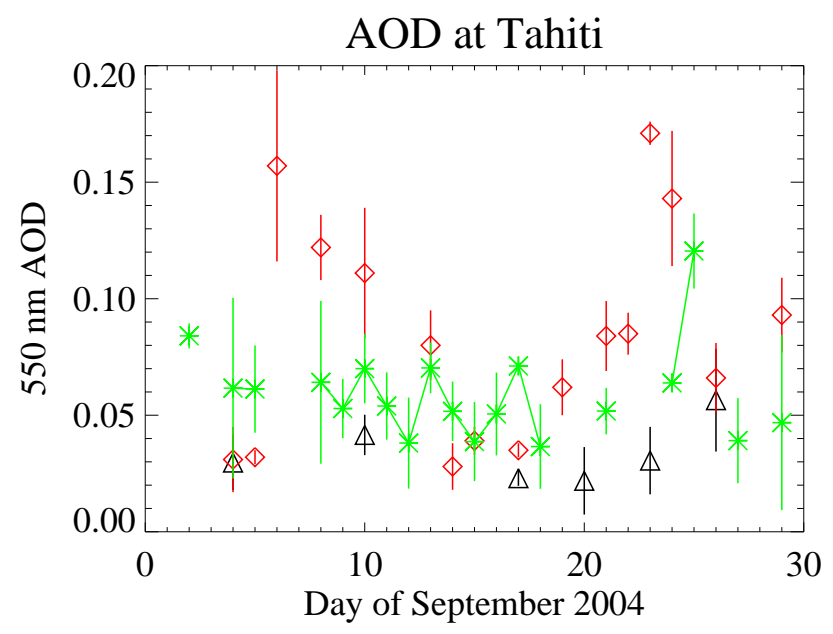

Fig. 21. Daily mean $550 \mathrm{~nm}$ AOD observed at the Tahiti AERONET site $\left(17.577^{\circ} \mathrm{S}, 149.06^{\circ} \mathrm{W}\right)$. Green symbols indicate AERONET measurements, and uncertainties the standard deviation of AOD throughout the day. Black triangles indicate AATSR and green diamonds MODIS-Terra, with error bars corresponding to the standard deviation of the $1^{\circ}$ grid cell in which Tahiti falls.

lead to a false enhancement in AOD of the order of 0.02 at $550 \mathrm{~nm}$. An analagous analysis has not been carried out for AATSR, although the cost function has been generally found to be successful at identifying cloud-contaminated scenes. Together these explain some of the discrepancy between MODIS and AATSR AODs.

Kokhanovsky et al. (2009) present an intercomparison study of aerosol retrievals over a black surface performed from synthetic data. Both the ORAC-AATSR and MODIS ocean aerosol retrieval algorithms participated in this study. In Kokhanovsky et al. (2009), the MODIS ocean algorithm 


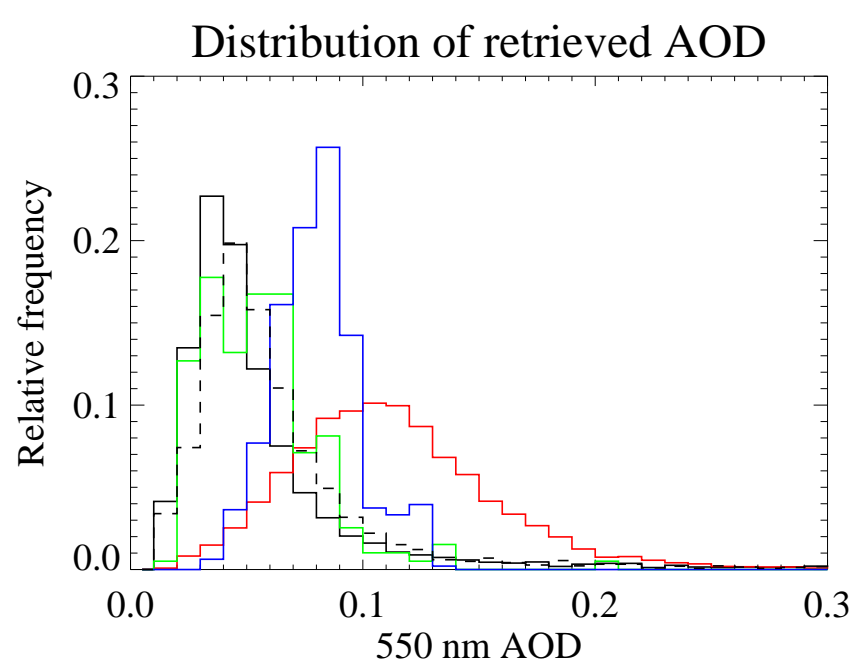

Fig. 22. Histogram of $550 \mathrm{~nm}$ AOD from each dataset. Black indicates AATSR and red MODIS-Terra. Both are calculated from a monthly mean on a $1^{\circ}$ grid, for only those cells where both instruments observe on the same day. Solid black indicates the standard AATSR retrieval, and dashed black when the wind speed is fixed at $6 \mathrm{~ms}^{-1}$ and overall surface reflectance fixed. Green indicates the Tahiti AERONET site, calculated from all observations during the month of September 2004. Blue indicates data from the open-Pacific MAN cruises Ronald H. Brown (2007-2008) and RV Melville (2009-2010), calculated from all observations taken within the study region. The scale indicates the proportion of all observations falling in that bin.

was observed to have a positive bias and ORAC-AATSR a slight negative bias in AOD. At low optical depths, as observed in this work, these biases were small (of the order 0.01 at $550 \mathrm{~nm}$ ). Additionally, it is not clear whether the retrievals using idealised synthetic data reflect accurately the performance of the retrieval using real measurements.

Calibration differences between the two instruments over these dark targets, and assumptions made about aerosol models, may also lead to disagreement. MODIS observes larger AODs on average than either the Tahiti AERONET site, or the MAN cruises, although this may reflect the conditions at these sampled locations, or biases in the sun-photometer retrieval algorithms. The same factors may explain the lower AODs as seen by AATSR as compared to the ground-based measurements. It is also possible that AATSR is overestimating the surface reflectance, and thereby underestimating the AOD. However, as shown in the previous section, the retrieval costs indicate that the retrieved states are consistent with the measurement and a priori uncertainty, with residuals reasonably unbiased (except in the nadir view at $1.6 \mu \mathrm{m}$ ), so it is difficult to diagnose a possible bias in retrieved AOD by examining fit statistics.

\section{Conclusions}

A sea surface BRDF model, drawing on the heritage of Koepke (1984), has been formulated for the visible and nearIR channels of the ATSR instruments (ranging from $550 \mathrm{~nm}$ to $1.6 \mu \mathrm{m})$. The model accounts for contributions to the observed reflectance from whitecaps, sun-glint and underlight. The model is discussed in the context of application to aerosol retrievals, although it is also suitable for use in cases of optically-thin clouds. It can be integrated over solar and viewing geometries to provide the DHR and BHR additionally required for the ORAC aerosol forward model. Furthermore, as ORAC is an optimal estimation algorithm, uncertainties in the parametrisations used in the BRDF model are propagated through into the forward model and retrieved state. As the brightness of the surface is permitted to vary in ORAC, unlike most other oceanic aerosol retrieval algorithms, some additional flexibility is available in the case where the assumed surface reflectance is incorrect. The new BRDF model offers improved coverage over previous methods, as retrievals are possible into the sun-glint region.

The new BRDF model has been implemented in the ORAC aerosol retrieval scheme and used to process one month of AATSR data in the south-eastern Pacific. Examination of retrieval statistics shows the assumed error budget to be generally appropriate, meaning the retrieved states are consistent with the measurements and a priori assumptions. The resulting field of AOD is intercompared with MODISTerra measurements in the whole region, AERONET observations at the Tahiti site, and MAN cruises over the same general area but different times. MODIS and AATSR show similar spatial distributions of AOD, although MODIS reports values which are larger and more variable. It is suggested that assumptions in the MODIS aerosol retrieval algorithm may lead to a positive bias in MODIS AOD over ocean regions where the wind speed is significantly higher than $6 \mathrm{~ms}^{-1}$. Other differences may arise due to residual cloud contamination, calibration differences, and aerosol model assumptions.

Acknowledgements. This work was supported by the UK Natural Environment Research Council (grant number NE/F001452/1). ECMWF are thanked for the wind data required as input for the ORAC retrieval, and NASA, ESA and the GlobColour team for the ocean colour data used. The NEODC is thanked for storing and supplying the Level 1 AATSR data ingested by the retrieval. NASA are acknowledged for the MODIS aerosol products used. B. Holben, A. Smirnov and the Maritime Aerosol Network PIs (D. Siegel, N. Nelson, P. Quinn, P. L. Croot, and C. M. Duarte) are thanked for their efforts in creating and maintaining the sun-photometer data as used in this investigation through the framework of the AERONET programme. Data collected on board NOAA Ronald H. Brown (2007-2008) and R/V Melville (2009-2010) were supplied by N. Nelson. Data collected on board NOAA Ronald H. Brown (2008) were supplied by P. Quinn. Data collected on board R/V 
Hesperides on the Humboldt-2009 cruise along the Chilean coast was supplied by C. M. Duarte. Data collected on board R/V Meteor during expedition M77 (legs 1-4) along the Peruvian and Chilean coast were supplied by P. L. Croot. The authors thank the three anonymous referees for their comments on the manuscript.

Edited by: A. A. Kokhanovsky

\section{References}

Anguelova, M. and Webster, F.: Whitecap coverage from satellite measurements: A first step toward modeling the variability of ocean whitecaps, J. Geophys. Res., 111, C03017, doi:10.1029/ 2005JC003158, 2006.

Austin, R. W.: The remote sensing of spectral radiance from below the ocean surface, Optical Aspects of Oceanography, edited by: Jerlov, N. G. and Nielsen, E. S., Academic Press, 317-344, 1974.

Barrot, G., Mangin, A., and Pinnock, S.: GlobColour product user guide, online available at: http://www.globcolour.info, last access: 2 December 2009, 2006.

Bennouna, Y. S., de Leeuw, G., Piazzola, J., and KusmierczykMichulec, J.: Aerosol remote sensing over the ocean using MSGSEVIRI visible images, J. Geophys. Res., 114, D23203, doi: 10.1029/2008JD011615, 2009.

Bréon, F. M. and Henriot, N.: Spaceborne observations of ocean glint reflectance and modeling of wave slope distributions, J. Geophys. Res., 111, C06005, doi:10.1029/2005JC003343, 2006.

Chen, C., Shi, P., and Zhan, H.: A local algorithm for estimation of yellow substance (gelbstoff) in coastal waters from SeaWiFS data: Pearl River estuary, China, Int. J. Remote Sensing, 24, 1171-1176, 2003.

Cox, C. and Munk, W.: Measurement of the roughness of the sea surface from photographs of the Sun's glitter, J. Opt. Soc. Am., 44, 838-850, doi:10.1364/JOSA.44.000838, 1954a.

Cox, C. and Munk, W.: Statistics of the sea surface derived from Sun glitter, J. Mar. Res., 13, 198-227, 1954b.

Devred, E., Sathyendranath, S., Stuart, V., Maass, H., Ulloa, O., and Platt, T.: A two-component model of phytoplankton absorption in the open ocean: Theory and application, J. Geophys. Res., 111, C03011, doi:10.1029/2005JC002880, 2006.

Dubovik, O., Holben, B., Eck, T. F., Smirnov, A., Kaufman, Y., Kind, M., Tanré, D., and Slutsker, I.: Variability and optical properties of key aerosol types observed in worldwide locations, J. Atmos. Sci., 59, 590-608, doi:10.1175/1520-0469(2002) 059 (0590:VOAAOP $>2.0 . C O ; 2,2002$.

Ebuchi, N. and Kizu, S.: Probability distribution of surface wave slope derived using sun glitter images from geostationary meteorological satellite and surface vector winds from scatterometers, J. Oceaonogr., 58, 477-486, doi:10.1023/A:1021213331788, 2002.

Forster, P., Ramaswamy, V., Artaxo, P., Berntsen, T., Betts, R., Fahey, D. W., Haywood, J., Lean, J., Lowe, D. C., Myhre, G., Nganga, J., Prinn, R., Raga, G., Schulz, M., and Van Dorland, R.: Changes in atmospheric constituents and in radiative forcing, Cambridge University Press, In: Climate Change 2007, the physical science basis. Contribution of Working Group 1 to the fourth assessment report of the Intergovernmental Panel on Climate Change, 2007.
Frouin, R., Schwindling, M., and Deschamps, P.-Y.: Spectral reflectance of sea foam in the visible and infra-red: In situ measurements and remote sensing implications, J. Geophys. Res., 101, 14361-14371, doi:10.1029/96JC00629, 1996.

Glantz, P., Nilsson, E. D., and von Hoyningen-Huene, W.: Estimating a relationship between aerosol optical thickness and surface wind speed over the ocean, Atmos. Res., 92, 56-68, doi: 10.1016/j.atmosres.2008.08.010, 2009.

Hale, G. M. and Querry, M. R.: Optical constants of water in the 200-nm to 200- $\mu \mathrm{m}$ wavelength region, Appl. Optics, 12, 555563, doi:10.1364/AO.12.000555, 1973.

Hess, M., Koepke, P., and Schult, I.: Optical properties of aerosols and clouds: The software package OPAC, Bull. Am. Met. Soc., 79, 831-944, doi:10.1175/1520-0477(1998)079, 1998.

Higurashi, A. and Nakajima, T.: Development of a TwoChannel Aerosol Retrieval Algorithm on a Global Scale Using NOAA AVHRR, J. Atmos. Sci., 56, 924-941, doi:10.1175/ 1520-0469(1999)056〈0924:DOATCA $\rangle$ 2.0.CO;2, 1999.

Holben, B. N., Eck, T. F., Slutsker, I., Tanré, D., Buis, J. P., Setzer, A., Vermote, E., Reagan, J. A., Kaufman, Y. J., Nakajima, T., Lavenu, F., Jankowiak, I., and Smirnov, A.: AERONET: A federated instrument network and data archive for aerosol characterization, Remote Sens. Environ., 66, 1-16, doi:10.1016/ S0034-4257(98)00031-5, 1998.

Huang, H., Thomas, G. E., and Grainger, R. G.: Relationship between wind speed and aerosol optical depth over remote ocean, Atmos. Chem. Phys. Discuss., 9, 24511-24529, 2009, http://www.atmos-chem-phys-discuss.net/9/24511/2009/.

Kaufman, Y. J., Remer, L. A., Tanré, D., Li, R.-R., Kleidman, R., Mattoo, S., Levy, R. C., Eck, T. F., Holben, B. N., Ichoku, C., Martins, J. V., and Koren, I.: A Critical Examination of the Residual Cloud Contamination and Diurnal Sampling Effects on MODIS Estimates of Aerosol Over Ocean, IEEE Trans. Geosci. Remote Sens., 43, 2886-2897, doi:10.1109/TGRS.2005.858430, 2005.

Koepke, P.: Effective reflectance of oceanic whitecaps, Appl. Optics, 23, 1816-1824, doi:10.1364/AO.23.001816, 1984.

Kokhanovsky, A. A.: Spectral reflectance of whitecaps, J. Geophys Res., 109, C05021, doi:10.1029/2003JC002177, 2004.

Kokhanovsky, A. A., Deuzé, J. L., Diner, D. J., Dubovik, O., Ducos, F., Emde, C., Garay, M. J., Grainger, R. G., Heckel, A., Herman, M., Katsev, I. L., Keller, J., Levy, R., North, P. R. J., Prikhach, A. S., Rozanov, V. V., Sayer, A. M., Ota, Y., Tanré, D., Thomas, G. E., and Zege, E. P.: The inter-comparison of major satellite aerosol retrieval algorithms using simulated intensity and polarization characteristics of reflected light, Atmos. Meas. Tech. Discuss., 2, 3369-3439, doi:10.5194/amtd-2-3369-2009, 2009.

Lehahn, Y., Koren, I., Boss, E., Ben-Ami, Y., and Altaratz, O.: Estimating the maritime component of aerosol optical depth and its dependency on surface wind speed using MODIS and QuikSCAT data, Atmos. Chem. Phys. Discuss., 10, 1983-2003, doi:10.5194/acpd-10-1983-2010, 2010.

Levenberg, K.: A Method for the Solution of Certain Non-linear Problems in Least-Squares, Q. Appl. Math., 2, 164-168, 1944.

Marquardt, D. R.: An Algorithm for the Least-Squares Estimation of Nonlinear Parameters, SIAM J. Appl. Math., 11, 431-441, doi:10.2307/2098941, 1963.

Martonchik, J. V., Diner, D. J., Kahn, R. A., Ackerman, T. P., Verstraete, M. M., Pinty, B., and Gordon, H. R.: Techniques 
for the retrieval of aerosol properties over land and ocean using multiangle imaging, IEEE Trans. Geosci. Remote Sens., 36(4), 1212-1227, doi:10.1109/36.701027, 1998.

Mermelstein, M. D., Shettle, E. P., Takken, E. H., and Priest, R. G.: Infrared radiance and solar glint at the ocean-sky horizon, Appl. Optics, 33, 6022-6034, doi:10.1364/AO.33.006022, 1994.

Mishchenko, M. I. and Travis, L. D.: Satellite retrieval of aerosol properties over the ocean using polarization as well as intensity of reflected sunlight, J. Geophys. Res., 102, 16989-17014, doi: 10.1029/96JD02425, 1997.

Mishchenko, M. I., Geogdzhayez, I. V., Cairns, B., Rossow, W. B., and Lacis, A. A.: Aerosol retrievals over the ocean by use of channels 1 and 2 AVHRR data: sensitivity analysis and preliminary results, Appl. Optics, 38, 7325-7341, doi:10.1364/AO.38. $007325,1999$.

Monahan, E. C. and Muircheartaigh, I. O.: Optimal powerlaw description of oceanic whitecap coverage dependence on wind speed, J. Phys. Oceanogr., 10, 2094-2099, doi:10.1175/ 1520-0485(1980)010<2094:OPLDOO $\rangle$ 2.0.CO;2, 1980.

Morel, A.: Optical properties of pure water and pure sea water, Optical Aspects of Oceanography, edited by: Jerlov, N. G. and Nielsen, E. S., Academic Press, 1-24, 1974.

Morel, A.: Optical modeling of the upper ocean in relation to its biogenous matter content (Case I waters), J. Geophys. Res., 93, 10749-10768, 1988.

Morel, A. and Gentili, B.: Diffuse reflectance of oceanic waters: its dependence on Sun angle as influenced by the molecular scattering contribution, Appl. Optics, 30, 4427-4438, doi: 10.1364/AO.30.004427, 1991.

Morel, A. and Prieur, L.: Analysis of variations in ocean color, Limnol. Oceanogr., 22, 709-722, 1977.

Nakajima, T. and Tanaka, M.: Effect of wind-generated waves on the transfer of solar radiation in the atmosphere-ocean system, J. Quant. Spectrosc. Ra., 29, 521-537, doi:10.1016/0022-4073(83) 90129-2, 1983.

Nicodemus, F. E., Richmond, J. C., Hsia, J. J., Ginsberg, I. W., and Limperis, T.: Geometrical Considerations and Nomenclature for Reflectance, Tech. rep., National Bureau of Standards, US Department of Commerce, Washington, DC, online available at: http://physics.nist.gov/Divisions/Div844/facilities/specphoto/ pdf/geoConsid.pdf, (last access: March 2010), 1977.

Nicolas, J.-M., Deschamps, P.-Y., and Frouin, R.: Spectral reflectance of oceanic whitecaps in the visible and infra-red: Aircraft measurements over open ocean, Geophys. Res. Lett., 28, 4445-4448, doi:10.1029/2001GL013556, 2001.

O'Brien, D. M. and Mitchell, R. M.: Retrieval of Surface Wind Speed and Aerosol Optical Depth over the Oceans from AVHRR Images of Sun Glint, J. Appl. Meteorol., 27, 1395-1403, doi: 10.1175/1520-0450(1988)027〈:ROSWSA〉2.0.CO;2, 1988.

Penner, J. E., Andreae, M., Annegam, H., Barrie, L., Feitcher, J., Hegg, D., Jayaraman, A., Leaitch, R., Murphy, D., Nganga, J., and Pitari, G.: Aerosols, their direct and indirect effects, Cambridge University Press, in: Climate Change 2001: the scientific basis. Contribution of Working Group 1 to the third assessment report of the Intergovernmental Panel on Climate Change, 2001.

Quan, X. and Fry, E. S.: Empirical equation for the index of refraction of seawater, Appl. Optics, 34, 3477-3480, doi:10.1364/AO. 34.003477, 1995.

Remer, L. A., Kaufman, Y. J., Tanré, D., Mattoo, S., Chu, D. A.,
Martins, J. V., Li, R.-R., Ichoku, C., Levy, R. C., Kleidman, R. G., Eck, T. F., Vermote, E., and Holben, B. N.: The MODIS Aerosol Algorithm, Products, and Validation, J. Atmos. Sci., 62, 947-973, 2005.

Rodgers, C. D.: Inverse methods for atmospheric sounding: Theory and Practice, Series on Atmospheric, Oceanic and Planetary Physics - Vol. 2, World Scientific, 2000.

Roesler, C. S., Perry, M. J., and Carder, K. L.: Modeling in situ phytoplankton absorption from total absorption spectra in productive inland marine waters, Limnol. Oceanogr., 34, 1510-1523, 1989.

Sano, I.: Optical thickness and Angstrom exponent of aerosols over the land and ocean from space-borne polarimetric data, Adv. Space Res., 34, 833-737, doi:10.1016/j.asr.2003.06.039, 2004.

Sathyendranath, S., Cota, G., Stuart, V., Maass, H., and Platt, T.: Remote sensing of phytoplankton pigments: A comparison of empirical and theoretical approaches, Int. J. Remote Sens., 22, 249-273, doi:10.1080/014311601449925, 2001.

Sayer, A. M.: Aerosol remote sensing using AATSR, Ph.D. thesis, University of Oxford, UK, 2008.

Schaepman-Strub, G., Schaepman, M. E., Painter, T. H., Dangel, S., and V., M. J.: Reflectance quantities in optical remote sensing definitions and case studies, Remote Sens. Environ., 103, 27-42, doi:10.1016/j.rse.2006.03.002, 2006.

Shaw, J. A. and Churnside, J. H.: Scanning-laser glint measurements of sea-surface slope statistics, Appl. Optics, 36, 42024213, doi:10.1364/AO.36.004202, 1997.

Shifrin, K.: An algorithm for determining the radiance reflected from the rough sea surface using MODIS-N satellite radiometer data, IEEE Trans. Geosci. Remote Sens., 39, 677-681, 2001.

Siegel, D. A., Wang, M., Maritorena, S., and Robinson, W.: Atmospheric correction of satellite ocean color imagery: the black pixel assumption, Appl. Optics, 33, 443-452, doi:10.1364/AO. 33.000443, 2000.

Smirnov, A., Holben, B. N., Eck, T. F., Dubovik, O., and Slutsker, I.: Effect of wind speed on columnar aerosol optical properties at Midway Island, J. Geophys. Res., 108(D24), 4802, doi:10.1029/ 2003JD003879, 2003.

Smirnov, A., Holben, B. N., Slutsker, I., Giles, D. M., McCLain, C. R., Eck, T. F., Sakerin, S. M., Macke, A., Croot, P., Zibordi, G., Quinn, P. K., Sciare, J., Kinne, S., Harvey, M., Smyth, T. J., Piketh, S., Zielinski, T., Proshuninsky, A., Goes, J. I., Nelson, N. B., Larouche, P., Radionov, V. F., Goloub, P., Moorthy, K. K., Matarresse, R., Robertson, E. J., and Jourdin, F.: Maritime Aerosol Network as a component of Aerosol Robotic Network, J. Geophys. Res., 112, D06204, doi:10.1029/2008JD011257, 2009.

Smith, D., Delderfield, J., Drummond, D., Edwards, T., Mutlow, C., Read, P., and Toplis, G.: Calibration of the AATSR instrument, Adv. Space Res., 28, 31-39, doi:10.1016/S0273-1177(01) 00273-3, 2001.

Smith, D., Poulsen, C., and Latter, B.: Calibration Status of the AATSR Reflectance Channels, in: 2008 ESA MERIS/(A)ATSR Workshop SP-666, 2008.

Smith, D. L., Mutlow, C. T., and Rao, C. R. N.: Calibration monitoring of the visible and near-infrared channels of the Along-Track Scanning Radiometer-2 by use of stable terrestrial sites, Appl. Optics, 41, 515-523, doi:10.1364/AO.41.000515, 2002.

Stamnes, K., Tsay, S.-C., Wiscombe, W., and Jayaweera, K.: Numerically stable algorithm for discrete-ordinate-method radiative transfer in multiple scattering and emitting later media, Appl. 
Optics, 27, 2502-2509, doi:10.1364/AO.27.002502, 1988.

Tanré, D., Kaufman, Y. J., Herman, M., and Mattoo, S.: Remote sensing of aerosol properties over oceans using the MODIS/EOS spectral radiances, J. Geophys. Res., 102, 16971-16988, doi:10. 1029/96JD03437, 1997.

Thomas, G. E., Poulsen, C. A., Sayer, A. M., Marsh, S. H., Dean, S. M., Carboni, E., Siddans, R., and Grainger, R. G.: OxfordRAL Aerosol and Cloud (ORAC): Aerosol retrievals from satellite radiometers, Springer (Berlin), in: Aerosol Remote Sensing Over Land, edited by: Kokhanvosky, A. A. and de Leeuw, G., 2009a.

Thomas, G. E., Poulsen, C. A., Sayer, A. M., Marsh, S. H., Dean, S. M., Carboni, E., Siddans, R., Grainger, R. G., and Lawrence, B. N.: The GRAPE aerosol retrieval algorithm, Atmos. Meas. Tech. Discuss., 2, 981-1026, doi:10.5194/amtd-2-981-2009, 2009.

Thomas, G. E., Poulsen, C. A., Siddans, R., Sayer, A. M., Carboni, E., Marsh, S. H., Dean, S. M., Grainger, R. G., and Lawrence, B. N.: Validation of the GRAPE single view aerosol retrieval for ATSR-2 and insights into the long term global AOD trend, Atmos. Chem. Phys., 10, 48491-4866, doi:10.5194/ acp-10-4849-2010 2010 .
Veefkind, J. P. and de Leeuw, G.: A new algorithm to determine the spectral aerosol optical depth from satellite radiometer measurements, J. Aerosol Sci., 29, 1237-1248, doi:10.1016/ S0021-8502(98)00032-9, 1998.

Vermote, E. F., Tanré, D., Deuzé, J. L., Herman, M., and Morcrette, J.-J.: Second Simulation of the Satellite Signal in the Solar Spectrum, 6S: An Overview, IEEE Trans. Geosci. Remote Sens., 35, 675-686, doi:10.1109/36.581987, 1997.

$\mathrm{Wu}$, J.: Sea-surface slope and equilibrium wind wave spectra, Phys. Fluids, 13, 741-747, doi:10.1063/1.1693978, 1972.

Závody, A. M., Mutlow, C. T., and Llewellyn-Jones, D. T.: A Radiative Transfer Model for Sea Surface Temperature Retrieval from the Along-Track Scanning Radiometer, J. Geophys. Res., 100, 937-952, doi:10.1029/94JC02170, 1995.

Zeisse, C. R.: Radiance of the ocean horizon, J. Opt. Soc. Am. A, 12, 2022-2030, doi:10.1364/JOSAA.12.002022, 1995.

Zhang, H. and Wang, M.: Evaluation of sun glint models using MODIS measurements, J. Quant. Spectrosc. Ra., 111(3), 492506, 2010. 